\title{
UN ANÁLISIS BIOARQUEOLÓGICO DE LOS ENTIERROS DE KuÉLAP, UN ACERCAMIENTO A LOS PATRONES DE MORFOLOGÍA Y VIDA
}

\author{
J. Marla Toyne a \\ Alfredo Narváez Vargas ${ }^{\mathrm{b}}$
}

\begin{abstract}
Resumen
Mediante el análisis bioarqueológico y biométrico de los restos óseos de Kuélap podemos probar los modelos de la naturaleza fisica atribuidos a los chachapoya, un grupo indígena mitificado por los inka en los documentos históricos. Fueron descritos como fuertes y feroces, pero también blancos y hermosos. Esta investigación explora los conceptos inka que distinguen de modo particular a la población chachapoya. Utilizando datos esqueléticos de una amplia muestra procedente de Kuélap, de más de 600 entierros, examinamos las estimaciones de estatura, proporciones, indicadores de esfuerzo, el tamaño corporal, modificación craneal y heridas traumáticas para reconstruir aspectos del aspecto físico de los hombres y mujeres chachapoya. Las comparaciones con los datos publicados son preliminares, pero pueden indicar si fueron diferentes a otras poblaciones precolombinas de la costa o la sierra. Siendo esta la primera aproximación a un perfil biomorfométrico de esta población, la reputación de los chachapoya no está confirmada, mostrando caracteristicas que los distinguen de otros grupos. Las identidades bioculturales de los pueblos antiguos pueden ser verificadas mediante varios indicadores y factores biogeográficos que influyeron la vida en el pasado.
\end{abstract}

Palabras clave: bioarqueología, morfometría, restos óseos, patrones mortuorios, etnohistoria, Chachapoyas.

\section{Abstract \\ A BIOARCHAEOLOGICAL ANALYSIS OF BURIALS FROM KUELAP; AN EXPLORATION OF PATTERNS IN MORPHOLOGY AND LIFESTYLE}

This paper presents an analysis of skeletal indicators of physical morphology reconstructed from burials recovered from Kuelap to test proposed models of the nature of the Chachapoya people whose characteristics have been mythologized from secondary historical documents based on Inka perceptions. Broadly defined as strong and fierce, but also fair and beautiful, this research explores Inka concepts of the physical distinctiveness of the Chachapoya people. Using skeletal data gathered from a large sample of over 600 burials from Kuelap, we examine estimations of stature, limb proportions, indicators of robusticity, body mass estimates, cranial modification, and traumatic injuries to reconstruct aspects of the physicality of the Chachapoya men and women. Comparisons can be made to the limited published literature to consider if the Chachapoya were distinct from other pre-Columbian populations either on the coast or in highland areas. While this is the first approximation of a morphometric profile of this Andean region, the Chachapoya's reputation is not overwhelmingly supported by a physical distinctiveness, although there are some specific features that distinguish them from other groups. The biocultural identities of past populations can be tested using various indicators to consider the influence of bio-geographical and cultural factors.

Keywords: Bioarchaeology, skeletal remains, metrics, mortuary practices, ethnohistory, Chachapoyas.

${ }^{a}$ University of Central Florida

Correo electrónico: j.marla.toyne@ucf.edu

${ }^{\mathrm{b}}$ Museo de Sitio de Túcume

Correo electrónico: luisalfredonarvaez@hotmail.com 


\section{Introducción}

Los antiguos chachapoya de Perú están caracterizados por los documentos históricos tempranos escritos por los primeros cronistas europeos, e influenciados por la percepción de los incas como hombres "fuertes» y mujeres «blancas y hermosas»; "guerreros fuertes y belicosos por naturaleza», descripciones que reflejan tanto características físicas como de comportamiento. Nos interesa considerar qué es lo que motivó estas descripciones, que probable tomaron lugar a partir de una mirada prejuiciosa durante la época de conquista inka y colonización espańola. Asimismo, estas crónicas parecen describir a los chachapoya como un pueblo distinto a otros en la antigüedad. Pero, ¿esta diferencia se basó en sus rasgos físicos? ¿ $\mathrm{O}$ en sus rasgos culturales? $\mathrm{Al}$ respecto podemos utilizar el análisis detallado de los restos óseos humanos (de Kuélap y otros sitios chachapoya, Fig. 1) para mejorar nuestro conocimiento de la naturaleza de esta población. Podemos caracterizar y reconstruir diferentes aspectos de sus vidas, salud, dieta y variación física en comparación con otras regiones de Perú.

Los estudios bioarqueológicos utilizan los restos humanos para caracterizar la salud biológica y la vida de pueblos antiguos reconociendo el hecho de que reflejan también una dinámica entre el ambiente y la experiencia social de los individuos. Muchas investigaciones en los Andes han proporcionado conocimiento de la dinámica política, las diferencias sociales, cambios económicos, migraciones, movilidad de las poblaciones y el impacto de la guerra, utilizando indicadores y patrones observables en los esqueletos (Andrushko et al. 2006; Gagnon 2008; Kellner y Schoeninger 2008; Torres-Rouff 2011; Tomasto 2013). En este artículo, exploramos la morfología de los chachapoya, su variación en estatura y forma física, utilizando una muestra de individuos del sitio arqueológico monumental de Kuélap para buscar evidencia de si realmente fueron únicos o especiales de alguna manera. Hacemos comparaciones con otras colecciones para desarrollar una apreciación inicial de esta población.

\subsection{Los modelos históricos: limitados pero provocadores}

Los datos etnohistóricos de los chachapoya son limitados y los investigadores continúan discutiendo el valor de las fuentes específicas, una situación que nos limita y genera una natural precaución al usar estas descripciones textuales. Es a partir de estas fuentes documentales que ocurre la definición de los chachapoya como grupo "cultural» o «macro-etnia», sobre la base de las descripciones del Inka ligadas a la región geográfica, aunque hubo otros subgrupos distintivos en el área (Fig. 2) (Lerche 1995; Schjellerup 1997: 30). Dentro de los textos históricos hay algunas representaciones interesantes y potencialmente útiles referidas a las cualidades y el carácter de la gente Chachapoya (Espinoza Soriano 1967; Lerche 1995; Schjellerup 2008; Ruiz Estrada 2011b). Podemos explorar estas fuentes, no literalmente, sino como reflexiones potenciales relacionadas con la población en la región para probar independientemente los correlatos arqueológicos.

La Tabla 1 presenta un resumen de varios textos que refieren a los chachapoya en las diversas fuentes históricas tempranas, que discuten cualidades comprobables. Debe indicarse que no hay relatos de primera mano desde la región de los chachapoya sino hasta fines del siglo XVI en algunos documentos jurídicos (Espinoza Soriano 1967). A pesar de que Cieza de León (1984 [1553]), por ejemplo, nunca visitó Chachapoyas, no es segura la fuente de sus datos. La crónica del fraile Blas Valera, un nativo de Chachapoyas (1963[1590]), fuente de Garcilaso de la Vega, ha sido discutida en tiempos recientes (Barraza Lescano 2003; Hyland 2003).

Hay también descripciones de los chachapoya como cazadores de cabezas trofeos (Salinas Loyola 1965[1571]:197) y el arte rupestre también sugiere esta practica — aunque no se ha encontrado ningún cráneo preparado (con huellas osteológicas como cortes y evidencia del colgante) (v.g.Verano 2001; Tung 2007) procedente de un sitio arqueológico ( $c f$. Koschmieder este número). Pero lo que dice Murúa (1987[1509]:150): «...los Chachapoya tomaron las cabezas de Chuquis Huaman y demás indios principales que habían muerto, y las pusieron en las puertas de sus 


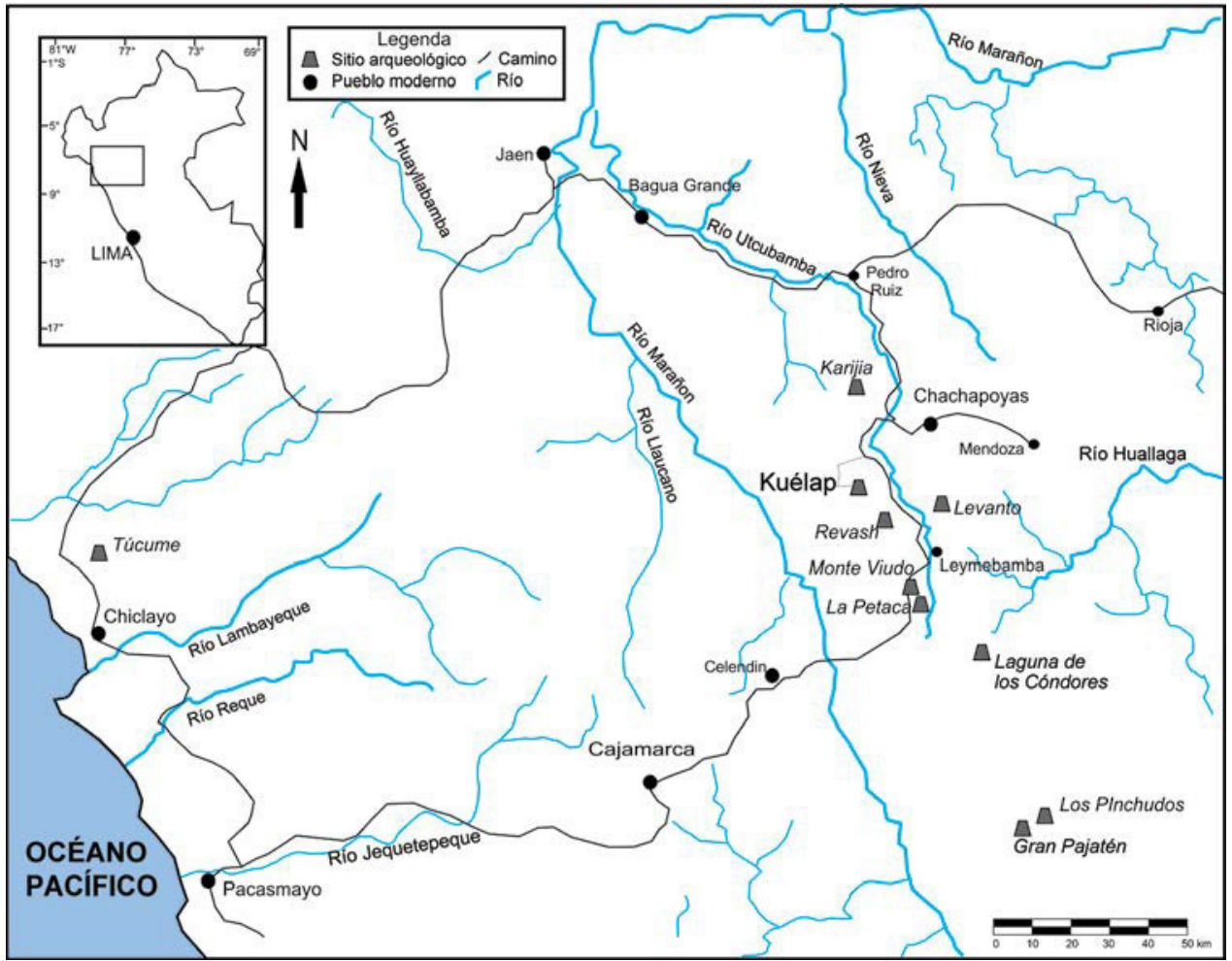

Figura 1. Mapa del norte de Perú con los sitios arqueológicos mencionados en el texto.

casas por trofeo e insignia de su valentía...» indica que las cabezas trofeos no eran tomadas de las víctimas muertas en guerra, sino que eran coleccionadas de tumbas saqueadas como símbolos de poder. Los chachapoya fueron personificados como una nación rebelde que resistió ferozmente la conquista inka, con por lo menos dos rebeliones contra la administración imperial (Pachacutiyamqui Salcamayhua 1963 [1620]; Cieza de León 1984 [1553]:162,187; Cobo 1990 [1653]:84; Garcilaso de la Vega 2004[1609]). Otros subgrupos dentro de la región fueron identificados como curanderos especializados, o herbolarios con gran conocimiento de plantas locales y su uso como remedios (Calancha 1972[1638]).

Aunque varios grupos no inkaicos fueron descritos en las crónicas, parece que los chachapoya fueron descritos ex profeso, como un grupo distinto por sus características físicas y algunos rasgos culturales respecto de otros grupos andinos. Así, ¿cómo probamos estas descripciones a partir del estudio de los restos óseos? ¿ ¿Son descripciones significativas a considerar? ¿Fueron realmente altos? Podemos explorar las medidas esqueléticas. ¿¿Fueron más fuertes o guerreros feroces? Quizás dentro de la morfología esquelética podemos ver patrones consistentes con el tamańo físico y fuerza. ¿Fueron hermosos y blancos? Es difícil de probar esto último bioarqueológicamente, o arqueológicamente, pero podemos considerar otros indicadores de diferenciación social o selección dentro de los restos biológicos. De mayor interés es la caracterización de la gente chachapoya como población única que vive en un ambiente geográfico distinto de otras poblaciones costeras o de la montańa. ¿Fueron los chachapoya distintos específicamente de otros grupos del Período Intermedio Tardío? ¿Hay características físicas consistentes con las condiciones medioambientales, el aislamiento genético, o el comportamiento cultural, que puede afectar el rango o tipos de estrés biológico evidente en estos restos óseos? 


\begin{tabular}{|c|c|}
\hline Cieza de León & \multirow{2}{*}{$\begin{array}{l}\text { Son estos indios naturales de los Chachapoyas los más blancos y agraciados de todos } \\
\text { cuantos yo he visto en las indias que he andado: y sus mugeres fueron tan hermo- } \\
\text { sas..,; porque son blancas y muchas muy dispuestas. }\end{array}$} \\
\hline (1984 [1553], LXXIII:229) & \\
\hline$(1880[1553]: 244)$ & $\begin{array}{l}\text { en los Chachapoyas halló Guayna Capac gran resistencia; tanto, que por dos ve- } \\
\text { ces volvió huyendo desbaratado a los fuertes que para su defensa se hacian; y con } \\
\text { favores que le vinieron, se revolvió sobre los Chachapoyanos y los quebrantó de tal } \\
\text { manera, que pidieron paz, cesando por su parte la guerra. Dióse con condiciones } \\
\text { provechosas al Inca, que mandó pasar muchos dellos a que residiesen en el mesmo } \\
\text { Cuzco, cuyos descendientes hoy viven en la mesma ciudad; tomó muchas mujeres, } \\
\text { porque son hermosas y agraciadas y muy blancas; puso guarniaciones ordinarias } \\
\text { con soladaos mitimaes, para que estuviesen por frontera... }\end{array}$ \\
\hline \multirow[t]{4}{*}{$\begin{array}{l}\text { Garcilaso de la Vega } \\
\text { (2004[1609]:VIII,i,67) }\end{array}$} & $\begin{array}{l}\text { Much a gente muy valiente, los hombres muy bien dispuestos y las mujeres hermosi- } \\
\text { sas en extreme. }\end{array}$ \\
\hline & $\begin{array}{l}\text { Los Chachapuyas respondieron resolutamenta que ellos estavan apercibidos par } \\
\text { alas armas y para morir en la defense de su liberta; que el Inca hiciesse que ellos no } \\
\text { querian ser vassallos. }\end{array}$ \\
\hline & ... lugar de varones fuertes... \\
\hline & ... la Guerra cruel de ambas partes, con muchas muertes y heridas. \\
\hline $\begin{array}{l}\text { Guaman Poma } \\
(1980[1615]: 161)\end{array}$ & $\begin{array}{l}\text { El Decimo Capitan, Challco Chima Inga, Caitan general de este reino, ... } \\
\text { Estos dichos capitanes fueron con su padre Guayna Capac Inga a la conquista } \\
\text { de las provincias de Chachapoyas, Canari, Ciccho, Purunay, Cico, Chupaycho, } \\
\text { Guancabilca... }\end{array}$ \\
\hline$(1980[1615]: 50)$ & $\begin{array}{l}\text {.. y era muy bilicosos yndios y brabos guerreros y fuertes: Cada uno de ellos enbes- } \\
\text { tian como leones y ci le matua al contrario, le sacaua el corazon y lo comian de } \\
\text { puero brabo y ferte gerrero y capitan. }\end{array}$ \\
\hline$(1980[1615]: 53)$ & $\begin{array}{l}\text { De como se poblauan los yndios en serros y altos por se ellos muy fuertes y babos, } \\
\text { que todo su trauajo era guerrear y uenserse unos con otros y quitarse quanto teienen } \\
\text { en aquel tiempo }\end{array}$ \\
\hline $\begin{array}{l}\text { Salinas Loyola } \\
\text { (1965[1571], III: 197) }\end{array}$ & ... los naturales muy belicosos, amigos de la guerra y de cortar cabecas.. \\
\hline Pizarro (1986[1557]:75) & ... xente de Guerra... \\
\hline $\begin{array}{l}\text { Sarmiento de Gamboa } \\
(1967[1572])\end{array}$ & $\begin{array}{l}\text { Huayna Capac... Los Chachapoyas habia ciertas tierras que podria conquistar y } \\
\text { de camino allanar los Chachapoyas, que se haian rebelado }\end{array}$ \\
\hline
\end{tabular}

Tabla 1. Descripciones de los atributos de los Chachapoyas por diferentes fuentes etnohistóricos. 
$16 \mathrm{r}$

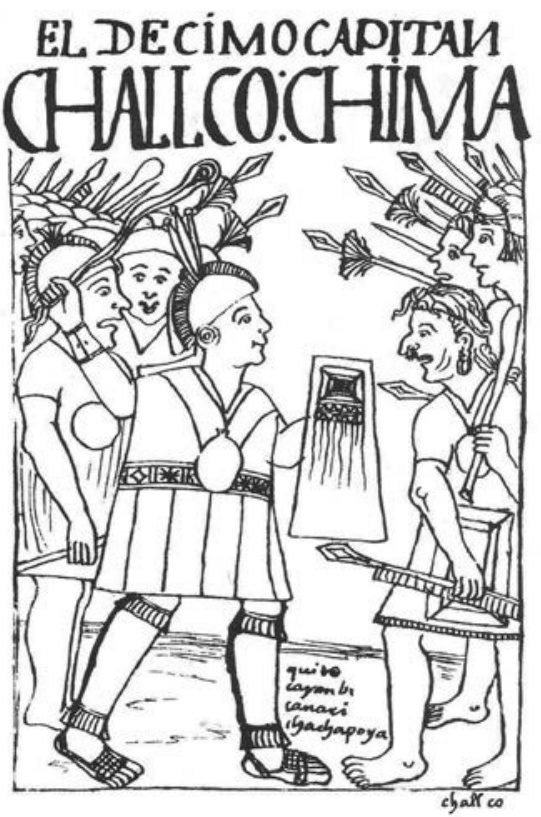

Figura 2. Guaman Poma (1980[1615]:116) pagina 161, una ilustración del 'decimo capitán Challoco Chima Inga,' quien conquistó la provincia de Chachapoyas entre otras. Este dibujo demuestra los Inkas a la izquierdo y un grupo que pudiera ser los Chachapoya.

\section{Objetivos de la investigación}

Esta investigación refleja una pequeña parte de los análisis bioarqueológicos en curso en Kuélap y la región más amplia Chachapoyas, respecto de los modelos de exploración de la salud, dieta, enfermedad y complejidad social (Toyne 2011; Toyne y Narváez Vargas 2014; Toyne 2015). De manera general, el objetivo de este estudio es caracterizar la muestra mortuoria en Kuélap, incluyendo la comparación con restos esqueléticos de diversos contextos funerarios (Fig. 3). Por lo tanto, estamos utilizando indicadores biológicos y esqueléticos de las historias individuales y modelos de experiencia colectiva del grupo. Estos datos bioarqueológicos incluyen la estimación de edad y sexo, observaciones de la patología dental, indicadores de estrés juvenil, lesiones traumáticas, enfermedades, diferencias nutricionales y pruebas de prácticas médicas tales como la trepanación craneana. Adicionalmente, estudios de isótopos estables (en tejidos humanos bien preservados) pueden utilizarse para reconstruir patrones dietéticos y movilidad residencial. Tenemos actualmente una cantidad abundante de datos sobre más de 600 individuos del sitio y los datos presentados aquí son una aproximación preliminar de algunos de los modelos más importantes.

En este artículo utilizamos la muestra ósea humana de Kuélap para explorar el rango de variación morfológica de la población mediante el estudio de los huesos. De esta manera, podemos acercarnos a la pregunta de si los chachapoya fueron más altos que otros grupos andinos, o si fueron más fuertes, o más robustos que los grupos costeños. La estatura, fuerza física y masa corporal de un adulto, representan características biológicas fundamentales en individuos y poblaciones. Otro marcador físico del ser humano en los Andes incluye la modificación craneal. Si los chachapoya resultaran ser una consecuencia del cruce entre las culturas de la selva baja y la sierra que también conectaban regiones costeras, ¿hay pruebas que de la modificación artificial craneal sugeriría una población mezclada de migrantes o foráneos? Finalmente, los tipos y modelos de trauma esquelético se pueden utilizar para explorar la apariencia física de los chachapoya y la naturaleza de las interacciones ambientales o interpersonales que pudieron haber dado lugar a una lesión. Por lo tanto, en este artículo exploramos la hipótesis que los chachapoya eran un grupo único, una condición que se refleja en sus esqueletos. 


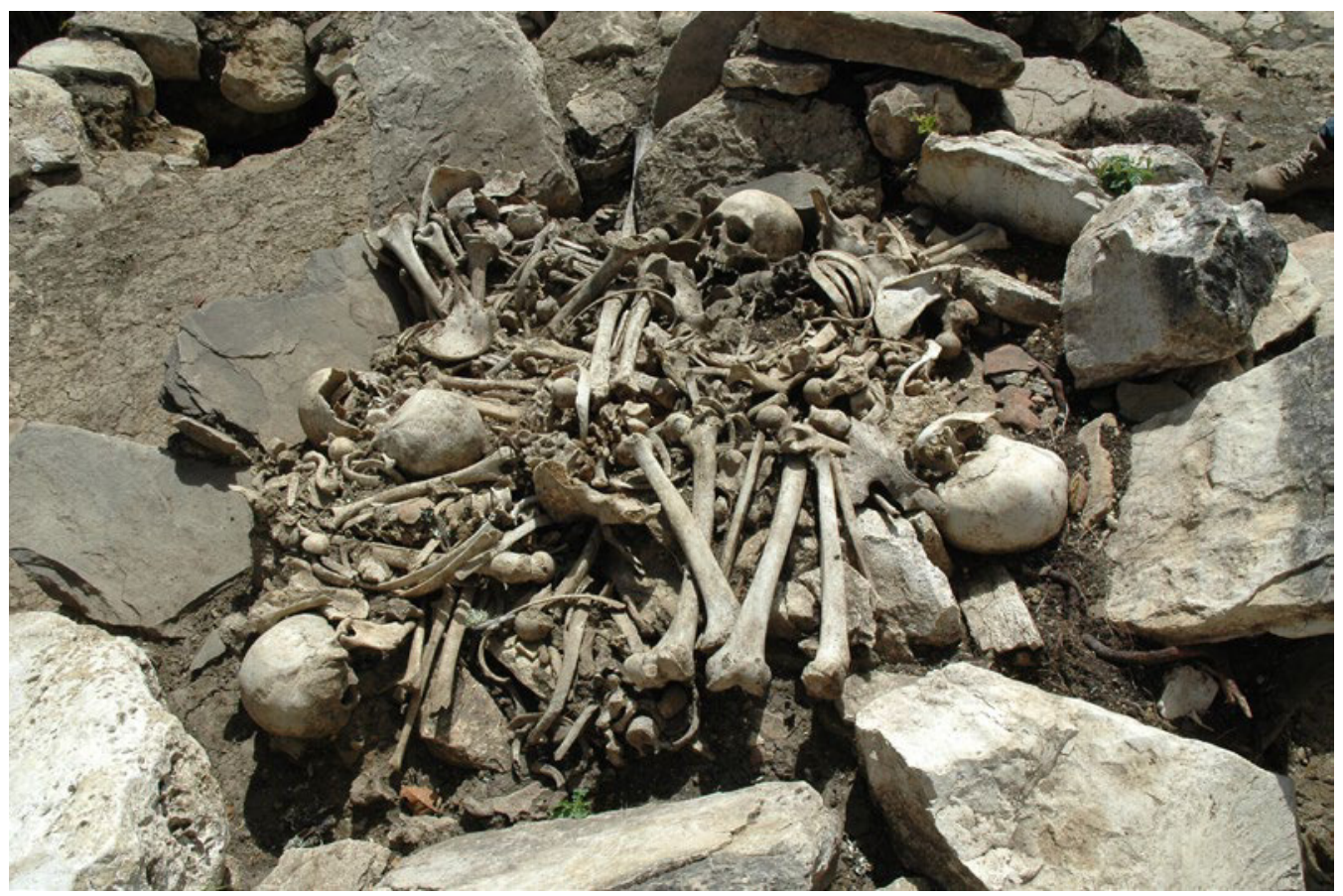

Figura 3. Foto de los esqueletos in situ en Kuélap, Tumba 2 del Pueblo Alto Central, una tumba de piedra concéntrica con múltiples entierros (el norte se ubica a la izquierdo) (foto por J.M. Toyne).

\section{Investigaciones bioarqueológicas previas}

Debemos indicar que, sobre todo, hay muy pocos sitios chachapoya excavados detalladamente, y pocos contextos mortuorios no huaqueados o destruidos completamente, en los cuales podemos explorar las preguntas referidas a la historia de la población, tendencias demográficas, características morfológicas y otros marcadores paleopatológicos importantes referidos a la salud, dieta y enfermedades en la región. Así, las investigaciones bioarqueológicas en la región Chachapoyas de los Andes nororientales del Perú, que utilizan restos óseos y cuerpos momificados han sido limitadas hasta ahora. Sin embargo, este enfoque viene avanzando y desarrollándose, incluyendo estudios de diversidad genética, condiciones paleopatológicas, homogeneidad poblacional y patrones de trauma en los esqueletos (Pia 1988; Ruiz Estrada 1994, 1999; Bracamonte 2002; Guillén 2002, 2003; Bracamonte 2004; Guillén, et al. 2004; Nystrom 2004, 2005, 2006, 2007; Gaither et al. 2008; Koschmieder y Gaither 2010; Toyne 2011; Nystrom y Toyne 2014; Toyne y Narváez Vargas 2014; Toyne 2015c, b; Toyne, et al. 2017). Hay gran potencial para la reconstrucción de las características biológicas, su variación en la región y una comparación con otros datos publicados más allá de la ceja de montańa. Hay algunas limitaciones para las comparaciones con los datos previamente publicados debido a la heterogeneidad en el tamaño de las muestras, la preservación de las colecciones esqueléticas, así como diversos intereses de la investigación, metodología e información de los datos.

La colección funeraria de la laguna de Los Cóndores, con más de 200 restos óseos y momias de adultos y niños, nos presenta un nivel excepcional de preservación, esperándose más publicaciones de las investigaciones sobre el perfil biográfico, los análisis antropométricos, descubrimientos radiográficos, bioquímica y estudios biomoleculares (ADN) (Guillén 2002; Guillén, et al. 2004; Nystrom 2009; Friedrich, et al. 2010; Guevara este número).

Muchos complejos arqueológicos contienen claramente evidencia de entierros con restos esqueléticos, pero estas colecciones son generalmente muy pequeñas y mal preservadas (Ruiz Barcellos 


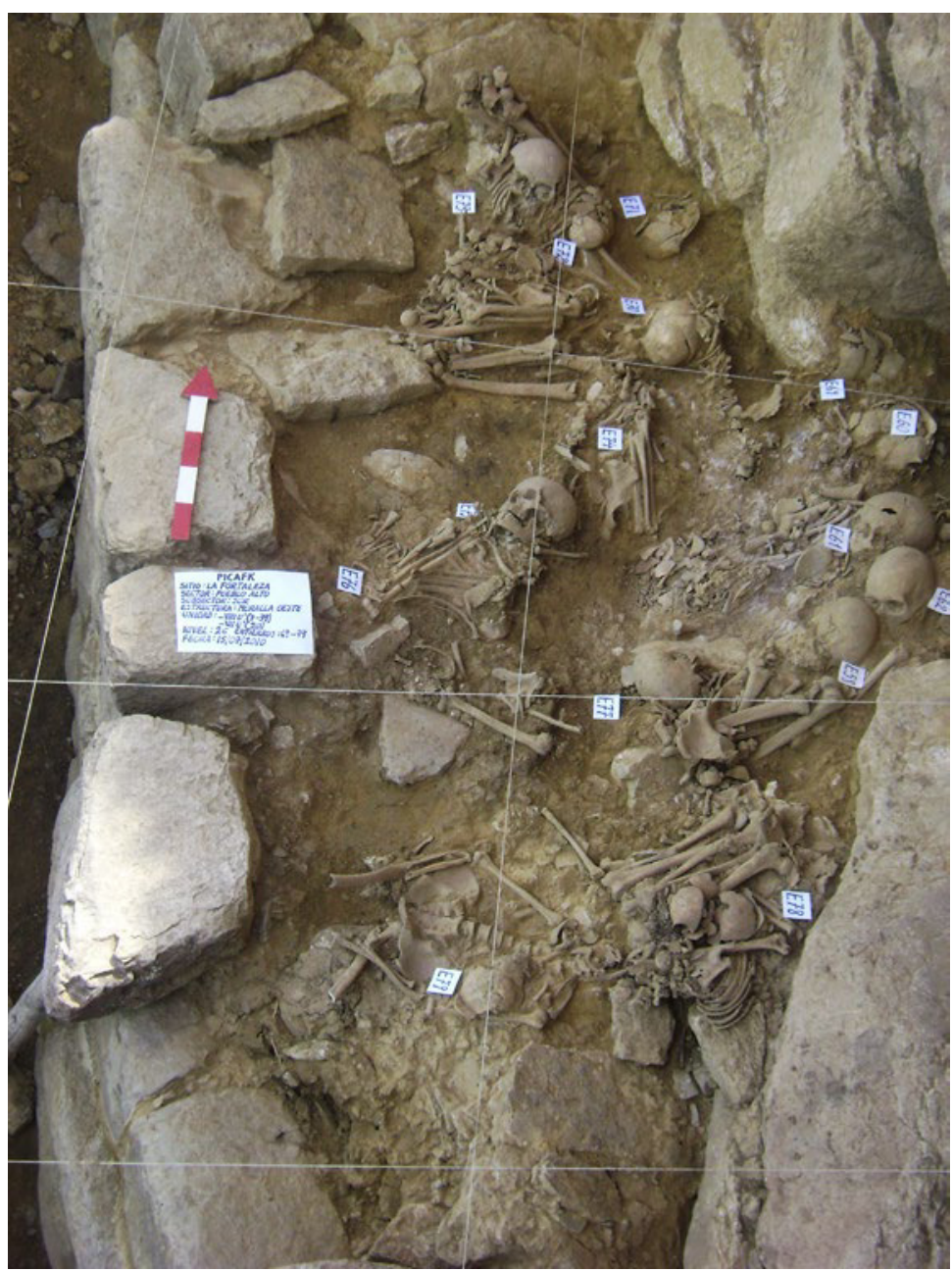

Figura 4. Foto de varios entierros secundarios en la Muralla Oeste (foto por E. Blas, Proyecto Arqueológico Kuélap).

2004, 2007; Guengerich 2014). Existe también una gran cantidad de sitios mortuorios en cuevas y mausoleos; pero las condiciones de estos restos, su acumulación y disposición como contextos secundarios, requieren una metodología específica. El trabajo de Toyne en el complejo mortuorio de La Petaca, cerca de Leymebamba, demuestra este potencial pues se recuperaron restos óseos de varias tumbas del acantilado. El análisis de la colección reveló que todas las tumbas incluían restos de individuos de un amplio rango de edades y ambos sexos (Gonzáles Valencia y Toyne 2014; Epstein y Toyne 2015). Desafortunadamente, debido al huaqueo extenso en el sitio, como tantos otros en la región, no se pudo recuperar individuos completos y los análisis óseos fueron limitados a observaciones de restos aislados y fragmentados. Los estudios preliminares sugieren que la morfología ósea de los entierros fue un poco distinta a los examinados en Kuélap, pero hay evidencia similar de trauma craneal, trepanaciones y otros indicadores de la falta de salud y enfermedades crónicas.

Avances recientes en la investigación de isótopos estables de materiales procedentes de Los Pinchudos, también proporcionan información sobre la variabilidad de la dieta y la movilidad de los chachapoya, datos que reflejan la complejidad social, cambios ocasionados por la conquista inka y la naturaleza de las élites enterradas en estas tumbas (Toyne et al. 2017). 


\section{Kuélap}

Kuélap es el primer asentamiento grande que ha producido un conjunto esquelético sustantivo de entierros a través de excavaciones sistemáticas, que pueden ser analizados como una excelente muestra de población mortuoria para la región. Localizado en el corazón del Alto Utcubamba, centro de la esfera cultural de la región Chachapoyas, sobre una imponente formación geológica, este sitio es uno de los más grandes de la región y arquitectónicamente presenta varias características únicas. El sitio tiene una larga historia del interés arqueológico desde su descubrimiento por Juan Crisóstomo Nieto en 1843 (Basadre 1892; Kieffer 1910; Langlois 1934; Bandelier 1940; Reichlen y Reichlen 1950; Horkheimer 1958; McGraw, et al. 1997; Bradley 2008; Kauffmann 2009), pero pocos investigadores han desarrollado excavaciones detalladas excepto Ruiz Estrada (1972) y Narváez Vargas (1987, 1996b, a, 2013). Las investigaciones en Kuélap, desde el 2000, han permitido un significativo avance en nuestros conocimientos de los diferentes sectores del sitio incluyendo los patrones arquitectónicos, los espacios funcionales y la variabilidad de los patrones de entierro (Narváez Vargas 2013).

Kuélap fue diseñado mediante la construcción de enormes y masivos muros de contención que crearon una plataforma de siete hectáreas, sobre la cual se construyeron más de 400 casas circulares de piedra. Algunos han sostenido que estas construcciones circulares están identificadas mejor como instalaciones de almacenamiento (Kauffmann 2009), pero la evidencia arqueológica consistentemente demuestra que fueron estructuras de uso residencial y doméstico, con áreas para cocinar, producción de alimentos, almacenaje y descanso (Narváez Vargas 2013). Los pisos interiores estuvieron limpios, asociados con material cerámico utilitario y doméstico en un gran rango de tipos y estilos, vasijas de almacenamiento y concentraciones de basura al exterior de las casas.

Hay, sin embargo, mucha variación en el tratamiento funerario, definiéndose por lo menos siete tipos de contextos en los cuales encontramos restos humanos en Kuélap: 1) fosas simples en los pisos dentro de las casas; 2) tumbas colectivas (en forma de colmena o cuadrada) (Fig. 3); 3) restos dentro de nichos en los muros (Fig. 4); 4) sarcófagos individuales muy destruidos (en el acantilado debajo del sitio); 5) mausoleos grandes a lo largo de Cerro La Barreta (en la pendiente noreste del cerro); 6) osarios y 7) cuevas/grutas naturales alrededor de la periferia del sitio (Ruiz Estrada 2009; Narváez Vargas 2013). Hay claramente algo importante al respecto del grado de variación mortuoria dentro de un solo sitio y el emplazamiento específico de los cuerpos dentro y alrededor del sitio - donde los entierros/ huesos/cuerpos fueron colocados específicamente en conexión con el paisaje, pero también con los espacios construidos dentro de la "ciudadela» donde vivió la población (dentro de los muros y los pisos residenciales) - . Algunos son entierros primarios, pero muchos son también colecciones de entierros secundarios. Por ejemplo, en los nichos en las murallas, los esqueletos están generalmente incompletos (muchos consisten en menos del $50 \%$ del cuerpo) y se observa que varios fueron puestos decúbito dorsal con las piernas flexionadas al pecho, mientras que otros individuos están representados como bultos de huesos desarticulados (Fig. 4). Se puede inferir por esta posición corporal y nivel de desarticulación que fueron traslados de otros contextos mortuorios, enfardelados en posición sentados flexionados (v.g. Guillén 2003), pero es imposible establecer su origen.

La cronología absoluta de la ocupación de Kuélap sugiere haber sido más temprana que estimaciones previas, a lo largo de casi 1000 años de ocupación ininterrumpida, con fechas radiocarbónicas próximas a los 500 d.C. hasta el Período Colonial Temprano (Narváez Vargas 2013). Pero los detalles cronológicos de los contextos mortuorios y los restos óseos requieren más refinamiento. Pudimos determinar que algunos contextos deben pertenecer a depósitos tempranos y tardíos en la historia del sitio. Sin embargo, hay varias tumbas cuya fecha relativa no podría ser definida. Está claro que la mayoría de los materiales cerámicos y las construcciones residenciales ocurrieron durante el Período Intermedio Tardío (c. 800-1470 d.C.), así como durante la ocupación inka de la región (1470-1535 d.C.). 
Mientras que hay evidencia clara de la presencia inka en Kuélap durante la ocupación final en términos de cerámica y espacios construidos, no existe evidencia de presencia inka en relación con la construcción en gran escala del sitio. Los cánones arquitectónicos de los edificios residenciales no cambian perceptiblemente, ni los modelos de entierro sugieren presencia del invasor quechua. La administración inka del sitio pudo haber sido bastante limitada físicamente, y no generó cambios espectaculares en la estructura de la población local o en las prácticas culturales. Por lo tanto, en esta etapa actual del conocimiento, mientras identificamos con claridad los entierros que preceden la presencia inka, elegimos tratar la colección ósea entera como una muestra unificada con el fin de explorar el rango de variación total. Esta colección incluye observaciones óseas de condiciones antemortem y de patología de todos los individuos recuperados del sitio, incluso el grupo de un mínimo de 118 individuos asociados con la «masacre», un evento tardío de una gran matanza en la Plataforma Circular al sur del sitio (Toyne y Narváez Vargas 2014). Los individuos están incluidos porque interpretamos que los restos pertenecen a los mismos habitantes de Kuélap.

\section{Metodología}

Se han excavado restos óseos humanos de Kuélap durante los últimos 30 años, los cuales están en estado variable de preservación. Estas colecciones han sido examinadas por la Dra. J. Marla Toyne durante los últimos 13 años. Esta investigación sigue los métodos osteológicos establecidos de observaciones métricas de los huesos largos y otras medidas (Ubelaker 1989; Buikstra y Ubelaker 1994) (Fig. 5). Los esqueletos fueron evaluados como individuos y la edad y el sexo fueron estimados en lo posible para observar diferencias de género. Los índices específicos de robustez son descritos más abajo. El trauma óseo fue registrado en el esqueleto, enfocándose en evidencias de violencia interpersonal (lesiones craneales). Identificamos fracturas que ocurrieron antemortem (con evidencia de curación) y las que fueron perimortem (que ocurrieron alrededor del momento de la muerte). Distinguimos entre las fracturas accidentales (ubicadas en los extremos del cuerpo) y fracturas de violencia interpersonal (ubicadas cerca al cráneo, cara y las manos del individuo) (Judd 2004). La modificación de la bóveda craneal ha sido identificada y sigue los estilos establecidos (Blom 2005). Los datos son ordinales y nominales así, los acercamientos estadísticos paramétricos y no-paramétricos fueron aplicados cuando ha sido necesario. Para comparaciones métricas (Heyerdahl et al. 1995; Toyne 2002, 2008, 2015a) se utilió la amplia muestra ósea de Túcume, una colección costera pero contemporánea (del Período Intermedio Tardío y del Horizonte Tardío) (n = 414, con una demografía similar de la muestra) y datos publicados de otros sitios chachapoya.

\section{Resultados}

\subsection{La demografía de la muestra de Kuélap}

Hasta la fecha se ha identificado un número mínimo de individuos $(\mathrm{n}=613)$ que ha sido examinado como restos óseos de diversos contextos mortuorios excavados en Kuélap. Hay muchos otros restos fragmentarios procedentes de la superficie de la Plataforma Circular y dentro de ella, también el Osario de la Estructura 9 que incluye un MNI de 75 individuos (Tran 2014), los cuales no son usados en este estudio. Sin embargo, la mayoría de los restos esqueléticos corresponden a individuos incompletos o fragmentarios que proceden de contextos secundarios o disturbados (incluyendo contextos con dificultades en el registro de excavación). Solamente $30 \%$ de los esqueletos están completos y el $75 \%$ incluye la presencia de la mayoría de los elementos óseos. La condición y la calidad de los restos clasifica como buena a moderada (en 52\% de los casos), pero el resto están mal preservados y fragmentados. La mayor parte de los esqueletos menos preservados proceden de entierros en los muros. Los individuos de tumbas y fosas ubicadas en los pisos de las casas están bien conservados. 


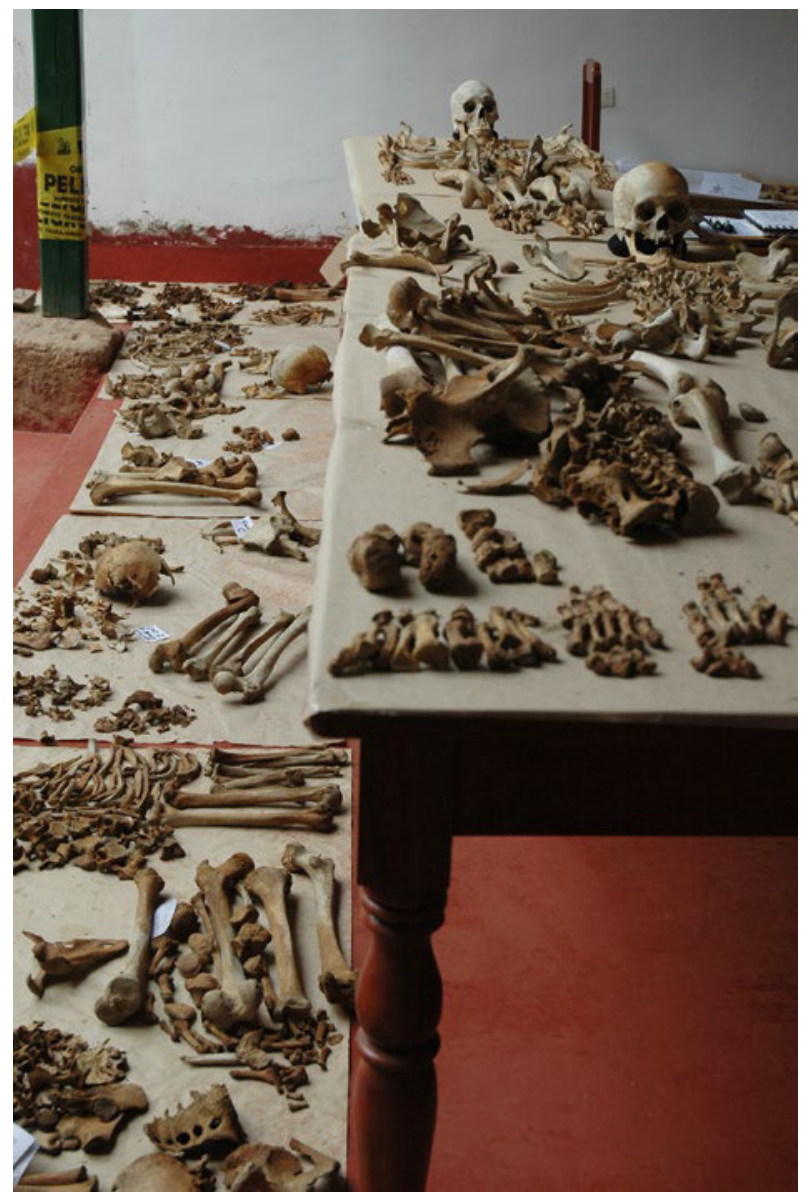

Figura 5. Foto de los restos óseos humanos en el laboratorio durante el examen osteológico (foto por J.M. Toyne).

La distribución de la edad y del sexo dentro de la muestra ósea (Tabla 2, Fig. 6) incluye individuos de ambos sexos (masculinos y femeninos) en proporciones similares, y todas las edades desde recién nacidos, niños, adultos jóvenes y adultos mayores $(-50+$ años $)-$. Si se tienen en cuenta a todos, la edad media de muerte en la muestra es de 23,2 ańos, la cual es una estimación simple del promedio de esperanza de vida. En la categoría adulto mayor, hay levemente más individuos femeninos $(-60 \%)$, mientras que la mayoría de los individuos masculinos parece haber fallecido en edad de adulto joven. Al mismo tiempo, la categoría más grande de edad ( $-30 \%$ de la muestra) es el grupo de adultos jóvenes. Comparando los modelos y a las estimaciones demográficas para las poblaciones preindustriales, esta muestra de Kuélap no sigue las expectativas, especialmente para los grupos más jóvenes (niños) donde tenemos una mortalidad más alta. Hay pocos restos recuperados fetales e infantiles. Esto se puede explicar generalmente por procesos arqueológicos y tafonómicos, por los cuales no se conservan bien los huesos más pequeños (los de los bebés), o razones culturales, pues los bebés pudieron haber sido enterrados en lugares distintos y estas áreas no han sido encontradas todavía. Los restos fetales e infantiles recuperados forman parte del grupo de los más jóvenes.

\subsection{Estimación de estatura de adultos}

La estatura humana es una métrica importante porque puede reflejar factores genéticos, así como cambios evolutivos o adaptativos en poblaciones humanas por permutas medioambientales, pero 


\begin{tabular}{lc}
\hline Categoría de edad & $\mathbf{n}$ \\
\hline Infante & 45 \\
Jóvenes & 118 \\
Adolescentes & 58 \\
Jovenes indeterminados & 0 \\
Todos jóvenes & 221 \\
Adulto jóven & 174 \\
Adulto medio & 120 \\
Adulto mayor & 22 \\
Adulto indeterminado & 62 \\
Todos adultos & 378 \\
\hline Total & 599 \\
\hline
\end{tabular}

Tabla 2. La distribución de la muestra por estimación de edad.

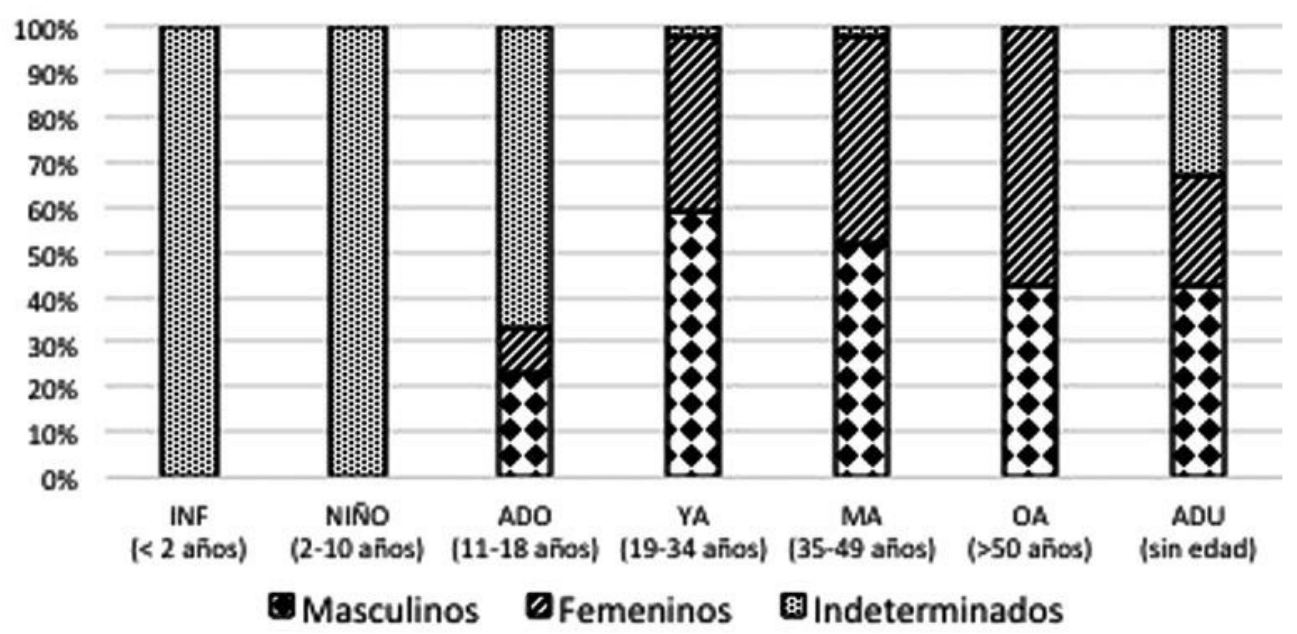

Figura 6. Distribución de la demografía de toda la muestra de Kuélap (INF= infante, menos de 2 años; NINONO=2 a 10 años; $A D O=$ adolescente, 11 a 18 años; $Y A=$ adulto joven, 19 a 24 años; $M A=$ adulto de edad media, 35 a 49 años; $O A=$ adulto mayor, más de 50 años).

también por aspectos de estrés fisiológico más breve ( $v . g$. ., episodios de estrés nutricional y de enfermedades durante el crecimiento y desarrollo moderados por influencias culturales) (Steckel 1995; Pomeroy y Stock 2012; Vercellotti et al. 2014). Siguiendo las interpretaciones simples y el cuerpo de reglas de Bergmann y de Allen relacionadas con la estatura, masa y las proporciones, se reflejan las condiciones climáticas. Las poblaciones más altas se encuentran generalmente en climas ecuatoriales más calientes. Las proporciones del cuerpo (largo de los miembros) y la masa del cuerpo, también pueden ser estimadas a partir de los restos óseos y proporcionar información sobre el aspecto físico. De hecho se recomienda usar estimaciones de la estatura solamente (Auerbach y Ruff 2010), pero aquí nuestro propósito es el inicio de comparaciones con otras muestras ya publicadas. 
La estatura fue estimada utilizando el formula de regresión de Genovés (1967) (basado en una muestra referente mexicana) y fue modificado por Del Ángel y Cisneros (2004) (lo cual resta aproximadamente 2,5 centímetros al largo del cadáver), utilizando métrica de los huesos largos, específicamente del largo del fémur para comparar con otros datos publicados. La Tabla 3 presenta el promedio de estatura para los hombres de Kuélap es 159,5 centímetros y un rango entre 150,9 y $165,8(-15$ centímetros $)(\mathrm{n}=53)$. El promedio de las mujeres es 148,4 centímetros y tiene un rango entre 138,1 y $155,7(\sim 17$ centímetros) $(n=22)$.

El primer detalle es el rango amplio en la variación en las muestras masculinas y femeninas. Los individuos masculinos son por término medio más altos que los individuos femeninos, pero ambos tienen rangos de variación similares (Fig. 7). Hay 6,6\% grados de dimorfismo sexual ${ }^{1}$ totales, lo cual es un promedio moderado en comparación con 7,8\% y a 10,4\% modelados para Los Pinchudos y La Petaca respectivamente, donde hay más diferencia de estatura estimada entre los individuos femeninos y masculinos. Hay coincidencia considerable en estimaciones de la estatura entre los sexos y no hay claramente una distribución bimodal que distinga a los individuos masculinos de los femeninos. Cuando el diámetro de la cabeza del fémur se traza contra la longitud femoral (usando las desviaciones medias y estándar), conseguimos una mejor discriminación entre los sexos, que sugieren que el promedio de altura y masa del cuerpo están correlacionadas con los individuos masculinos más grandes que los individuos femeninos (Fig. 8). Pero es importante observar que hay individuos masculinos bajos y también individuos femeninos altos en este grupo.

Los pocos datos de otros sitios chachapoya demuestran que las estimaciones de estatura no son diferentes estadísticamente de los de Kuélap. Los Pinchudos y La Petaca son colecciones de restos óseos desafortunadamente mezclados, con la determinación de sexo insegura. Sin embargo, en La Petaca los pocos individuos asignados con sexo, son un poco más altos. Si las diferencias de la situación social se expresan en la elaboración de la tumba, entonces las tumbas de élite de La Petaca contienen individuos que son ligeramente más altos que los de Kuélap. Entonces la estatura quizás está relacionada a un mejor estado de salud y acceso a recursos durante la juventud del individuo en relación con su rango social (Steckel 1995).

En comparación con Túcume, la amplia muestra ósea de un sitio costero del Período Intermedio Tardío, podemos ver que hay diferencias significativas en estatura entre los individuos masculinos y los femeninos (todos los individuos, prueba de $\mathrm{t}=-3,435, \mathrm{p}=0,001$; hombres, $\mathrm{t}=-4,723, \mathrm{p}=0,000$; mujeres, $\mathrm{t}=-3,036, \mathrm{p}=0,005$ ), donde los individuos de Kuélap son más altos (Tabla 3). En comparación con otras muestras andinas, estos hombres y mujeres son un poco más altos en algunos casos, pero hay promedios y rangos similares. Las comparaciones estadísticas no muestran ninguna diferencia entre hombres de Kuélap y Farfán — una muestra costera del Período Intermedio Tardío de individuos élites_, o Punta Lobos — una matanza represalia del Período Intermedio Tardío (Verano y Toyne 2011)_, sino diferencias significativas comparadas con la muestra del Horizonte Tardío de Machu Picchu, en la sierra sur de Perú (Verano 2003). Sin embargo, la muestra de Machu Picchu incluye un conjunto altamente mezclado de gente diferente procedente de las regiones conquistadas por el imperio Inka, incluyendo los de bajo estatus e individuos posiblemente costeros. Las mujeres de Kuélap son perceptiblemente más altas que las de Machu Picchu, así como las mujeres de élite en Farfán.

\section{3. Índices morfológicos y robusticidad de los huesos largos}

Otra métrica calculada para este grupo y otras muestras andinas es el índice crural, sobre la base de las proporciones de la pierna que compara la longitud del segmento tibial al segmento femoral (longitud tibial/longitud femoral X 100). Esta métrica se crea para reflejar el tamaño del cuerpo total y las condiciones ambientales (piernas más largas en climas más caliente y secos, y piernas más cortas en locaciones frías o de altitud).

Los índices crurales para la muestra de Kuélap son 83,0 para los individuos masculinos y 81,1 para los individuos femeninos, que son perceptiblemente diferentes. Comparado con Túcume, 


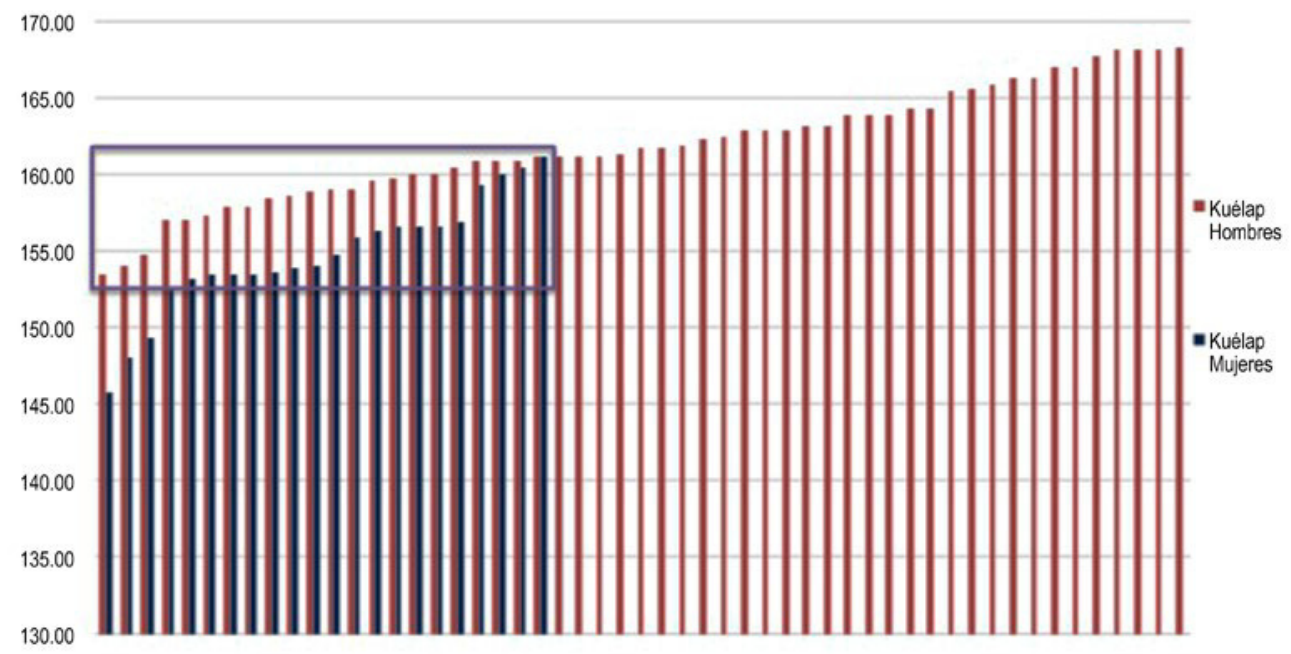

Figura 7. Estimaciones de estatura en centímetros de los individuos de Kuélap, masculinos y femeninos.

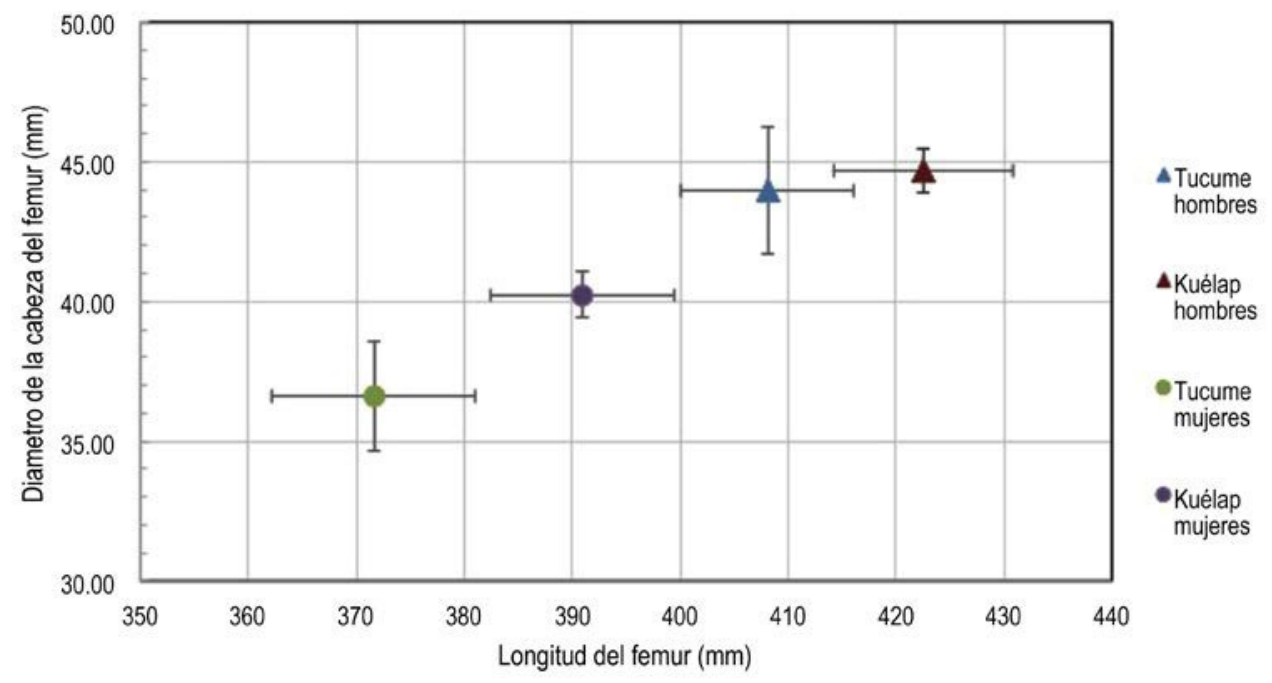

Figura 8. Correlación entre el largo del fémur y el diámetro de la cabeza del fémur de las mujeres y hombres.

también hay diferencias significativas en los índices crurales entre las mujeres y los hombres. Los individuos de Kuélap tienen índices crurales más bajos, indicando que los miembros inferiores son más cortos. Los valores generados en la Tabla 4 son comparados con otras poblaciones andinas más ampliamente definidas (calculado por Pomery y Stock 2012), pero también con otras poblaciones mundiales (Auerbach 2010). No hay una diferencia significativa con el Valle del Mantaro, otro grupo andino de altura, pero se debe notar que la muestra es muy pequeńa. Hay una diferencia 


\begin{tabular}{|c|c|c|c|c|c|c|c|c|c|c|c|c|c|c|c|c|c|c|c|c|}
\hline 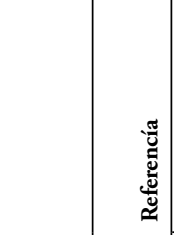 & 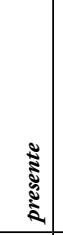 & 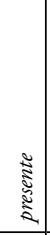 & 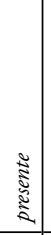 & 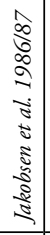 & 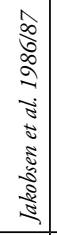 & 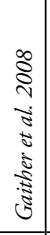 & 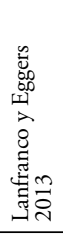 & 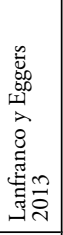 & 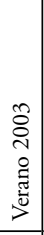 & 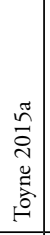 & 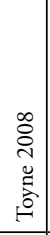 & 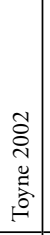 & 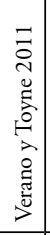 & 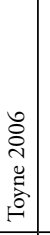 & 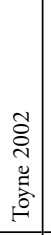 & 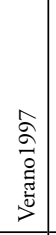 & 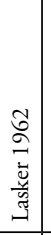 & 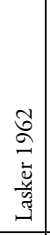 & 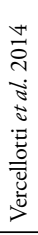 & 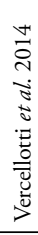 \\
\hline 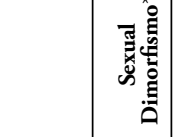 & $\stackrel{6}{6}$ & $\stackrel{尺}{\stackrel{2}{\imath}}$ & 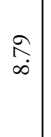 & $\underset{\infty}{\vec{\infty}}$ & $\underset{\infty}{\vec{\infty}}$ & & $\underset{f}{\vec{F}}$ & 菅 & $\underset{+}{\stackrel{\leftrightarrow}{*}}$ & $\stackrel{\infty}{\vec{b}}$ & & $\stackrel{\mathbb{N}}{\wedge}$ & & $\begin{array}{l}\overrightarrow{0} \\
\infty\end{array}$ & 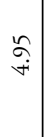 & $\stackrel{\sim}{\therefore}$ & $\begin{array}{l}\hat{0} \\
\infty\end{array}$ & $\underset{\infty}{\vec{\alpha}}$ & $\begin{array}{l}\hat{0} \\
\infty\end{array}$ & : \\
\hline$\dot{\leftrightarrow}$ & $\underset{\forall}{\stackrel{q}{*}}$ & 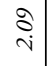 & ' & $\cong$ & $\cong$ & , & $\underset{\forall}{\stackrel{\rightleftarrows}{\forall}}$ & 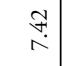 & $\underset{\leftrightarrow}{\overrightarrow{+}}$ & $\underset{\sigma}{\sigma}$ & ' & $\underset{\sim}{\vec{r}}$ & & $\stackrel{\vec{m}}{\stackrel{m}{m}}$ & $\underset{\forall}{\stackrel{f}{*}}$ & $\stackrel{\pi}{a}$ & $\stackrel{\pi}{a}$ & $\frac{\pi}{a}$ & in & $\underset{+}{\stackrel{\leftrightarrow}{+}}$ \\
\hline $\begin{array}{l}\text { 品 } \\
\text { 总 }\end{array}$ & $\begin{array}{l}0 \\
\stackrel{3}{2}\end{array}$ & $\stackrel{0}{\stackrel{0}{0}}$ & 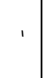 & & . & . & $\underset{\exists}{ }$ & $\stackrel{n}{\varrho}$ & $\underset{\sim}{\mathscr{\Xi}}$ & $\begin{array}{l}0 \\
\stackrel{0}{\longrightarrow}\end{array}$ & . & $\underset{\overbrace{}}{\tilde{\sigma}}$ & ' & $\hat{\ddot{g}}$ & $\stackrel{\circ}{=}$ & $\hat{\mathrm{S}}$ & $\frac{\pi}{z}$ & 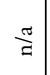 & $\stackrel{\infty}{\wedge}$ & $\vec{n}$ \\
\hline 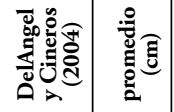 & 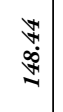 & 矛 & $\widehat{\approx}$ & & ' & ' & . & ' & & ' & . & ' & & $\begin{array}{l}\stackrel{8}{ } \\
\underset{J}{ \pm}\end{array}$ & ' & & ' & ' & ' & \\
\hline 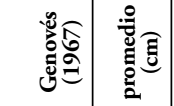 & $\begin{array}{l}\vdots \\
\dot{v} \\
0\end{array}$ & 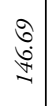 & $\begin{array}{l}\partial \\
\dot{Q} \\
\dot{D}\end{array}$ & \begin{tabular}{l} 
勇 \\
\multirow{+}{*}{}
\end{tabular} & 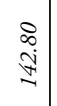 & . & 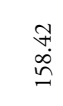 & 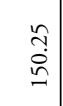 & 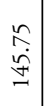 & 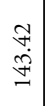 & ' & 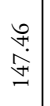 & & $\begin{array}{l}\stackrel{\overrightarrow{0}}{\vec{J}} \\
\end{array}$ & $\begin{array}{l}\stackrel{2}{\circ} \\
\stackrel{+}{ \pm}\end{array}$ & 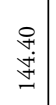 & $\begin{array}{l}\infty \\
\infty \\
\stackrel{+}{+}\end{array}$ & $\frac{2}{ \pm}$ & 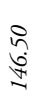 & ڤે \\
\hline$\Rightarrow$ & $\tilde{m}$ & $n$ & - & $\ddot{v}$ & $a$ & & $\infty$ & $N$ & $\stackrel{\circ}{\circ}$ & $\simeq$ & ' & 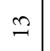 & & $\stackrel{\infty}{=}$ & $m$ & 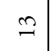 & $\hat{a}$ & $\vec{\sigma}$ & $\infty$ & 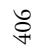 \\
\hline$\dot{\theta}$ & $\begin{array}{l}\hat{\sigma} \\
\dot{m}\end{array}$ & $\begin{array}{l}\grave{N} \\
\stackrel{2}{*}\end{array}$ & $\underset{⿱}{*}$ & ' & ' & $\vec{\nabla}$ & $\hat{\delta}$ & $\hat{\tilde{n}}$ & $\stackrel{\infty}{\grave{r}}$ & $\tilde{m}$ & $\stackrel{m}{m}$ & $\begin{array}{l}\tilde{N} \\
\mathrm{i}\end{array}$ & $\underset{\sim}{\mathbb{r}}$ & 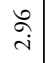 & 莕 & $\stackrel{\pi}{\Xi}$ & $\stackrel{\Xi}{\Xi}$ & $\stackrel{\Xi}{\Xi}$ & $\stackrel{\overbrace{}}{\stackrel{1}{r}}$ & $\stackrel{\stackrel{\cap}{n}}{n}$ \\
\hline $\begin{array}{l}\text { 品 } \\
\text { 至 }\end{array}$ & $\begin{array}{l}\vec{\infty} \\
\vec{\nabla}\end{array}$ & $\hat{\forall}$ & $\begin{array}{l}\infty \\
\infty \\
\infty\end{array}$ & & ' & $\widetilde{6}$ & $\tilde{o}$ & $=$ & $\stackrel{\leftrightarrow}{\circ}$ & $\stackrel{7}{2}$ & $\stackrel{7}{2}$ & $\stackrel{\infty}{\dot{\infty}}$ & $\stackrel{\mathbb{2}}{\stackrel{2}{\beth}}$ & 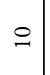 & $\stackrel{\sharp}{2}$ & $\stackrel{\bullet}{\bullet}$ & $\stackrel{\pi}{\nexists}$ & $\stackrel{\pi}{a}$ & $=$ & $\hat{\curvearrowright}$ \\
\hline
\end{tabular}

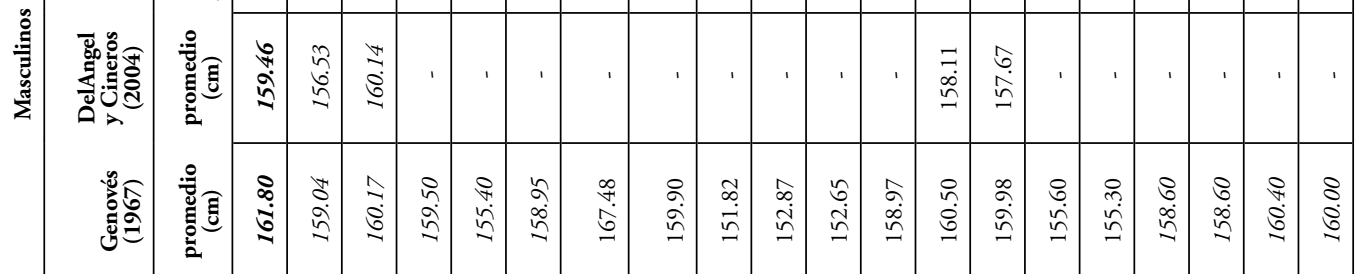

है

3

ปับ

sั

5o

s

क्ष

ชั

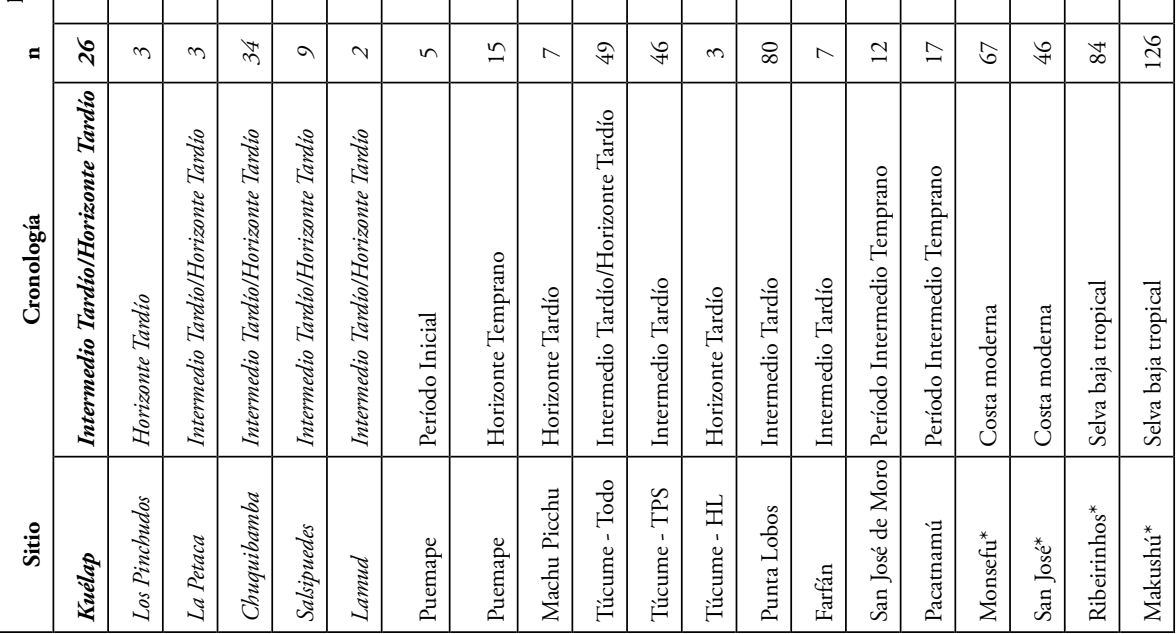


con otro grupo de altura de San Pedro de Atacama, pero pertenecen a un medioambiente desértico. Es interesante observar que la muestra de Kuélap es más similar a las poblaciones árticas que otras poblaciones adaptadas a climas calientes, al igual que la muestra más temprana del sitio costeño de Paloma. Esto puede sugerir que las piernas de proporciones más cortas están ligadas a adaptaciones a un clima más frío, los grupos costeros se desarrollaron lejos de esta morfología, en las montańas las proporciones más cortas se conservan debido al clima, a la altitud y a la geografía.

De modo semejante, exploramos la relación de la morfología del brazo usando la métrica de dos variables de las proporciones humerales y del hombro para generar un índice de robusticidad (diámetro de la cabeza de húmero/longitud del húmero X 100). Mientras que la biométrica de dos variantes son acercamientos simplificados para la morfométrica de óseos, el análisis geométrico y de múltiples variantes (Ruff 1992) pueden revelar diferencias más complejas y relaciones estadísticas entre rasgos óseos relacionados con la forma, tamaño y fuerza ósea (y entonces fuerza del cuerpo). Estos resultados son preliminares y comparativos para ver cómo los datos se presentan entre Kuélap y otros grupos andinos. No hay diferencia en esta métrica entre los hombres y mujeres de Túcume. Hasta ahora no hay otros datos publicados, aunque hay potencial para futuros estudios (Pomeroy y Stock 2012; Pomeroy 2013).

Finalmente, las estimaciones de masa corporal utilizan el diámetro de la cabeza del fémur para acceder a la contextura física y estatura de los chachapoya. Los datos presentados en Tabla 5 estiman una diferencia significativa entre el tamaño del cuerpo de los hombres y las mujeres de Kuélap, pero como se puede observar en esta tabla, hay también una diferencia entre los individuos de Túcume. Eso sugiere que los individuos de Kuélap son más robustos y más altos respecto de la muestra de la costa de Perú.

\begin{tabular}{|l|l|c|c|c|c|c|}
\cline { 3 - 6 } \multicolumn{1}{c|}{} & \multicolumn{2}{c|}{ Masculinos } & \multicolumn{2}{c|}{ Femeninos } & \multirow{2}{*}{} \\
\cline { 2 - 6 } \multicolumn{1}{c|}{} & Altitud m.s.n.m./cronología & $\mathrm{n}$ & Promedio (S.D.) & $\mathrm{n}$ & Promedio (S.D.) & \\
\hline Kuélap & $3,000 \mathrm{~m} /$ d.C.800-1532 & 50 & $83.1(2.3)$ & 48 & $81.1(2.0)$ & (presente) \\
\hline Túcume & $100 \mathrm{~m} /$ d.C. $1000-1532$ & 48 & $84.5(2.3)^{*}$ & 11 & $85.1(1.4)^{*}$ & (presente) \\
\hline Paloma & $220 \mathrm{~m} / 4500-2750$ a.C. & 0 & - & 3 & $82.8(1.7)$ & (Pomery y Stock 2012) \\
\hline $\begin{array}{l}\text { Valle de } \\
\text { Mantaro }\end{array}$ & $3,200 \mathrm{~m} /$ d.C. 1000-1400 & 2 & $84.1(4.1)$ & 2 & $84.4(0.7)$ & (Pomery y Stock 2012) \\
\hline $\begin{array}{l}\text { San Pedro de } \\
\text { Atacama }\end{array}$ & $2,400 \mathrm{~m} / 100$ a.C. - d.C & 83 & $85.6(1.7)^{*}$ & 53 & $85.6(1.7)^{*}$ & (Pomery y Stock 2012) \\
\hline Ártico & 1240 & 157 & $81.8(2.3)^{*}$ & 117 & $81.4(2.2)$ & (Auerbach y Ruff (2010) \\
\hline Temperado & (moderno) & 287 & $85.1(1.9)^{*}$ & 245 & $84.2(2.0)^{*}$ & (Auerbach y Ruff (2010) \\
\hline $\begin{array}{l}\text { Grandes } \\
\text { llanuras }\end{array}$ & (moderno) & 91 & $85.7(2.2)^{*}$ & 70 & $85.5(2.3)^{*}$ & (Auerbach y Ruff (2010) \\
\hline
\end{tabular}

$(*$ diferencia significativa $\mathrm{p}<0.001)$

Tabla 4. La estimación de los indices crurales de Kuélap y otros grupos andinos.

\begin{tabular}{|l|c|c|c|c|c|c|}
\cline { 2 - 7 } \multicolumn{1}{c|}{} & \multicolumn{3}{c|}{ Masculino } & \multicolumn{3}{c|}{ Femenino } \\
\cline { 2 - 7 } \multicolumn{1}{c|}{} & $\mathrm{n}$ & Promedio & S.D. & $\mathrm{n}$ & Promedio & S.D. \\
\hline Kuélap & 105 & 63.86 & 4.4 & 52 & 55.53 & 3.97 \\
\hline Túcume & 64 & 60.39 & 6.07 & 39 & 50.34 & 4.18 \\
\hline
\end{tabular}

Tabla 5. La estimación de la masa corporal de Kuélap y Túcume. 


\subsection{Modificación craneal artificial}

A través de los Andes prehispánicos, la modificación craneal se ha observado en diversas colecciones esqueléticas y una gran cantidad de investigaciones se ha enfocado en la identificación de las formas modificadas y la distribución de cráneos modificados en y entre poblaciones (Torres-Rouff 2002; Blom 2005). Hay una cierta discusión en cuanto a la intencionalidad de aplanar o deformar la bóveda craneal, especialmente en sitios donde la forma de modificación es sutil y hay evidencia del uso de una cuña (Verano 1997). En comparación, hay regiones donde la modificación craneal era importante, como Nasca y Lambayeque, pero en los períodos más tardíos los datos en diferentes regiones no son tan claros.

Específicamente en la costa norte, hay un rango de variación que no parece estar correlacionada con otros marcadores de identidad o estatus social, como sucede en la costa sur (Torres-Rouff 2002; Lozada y Buikstra 2005). Las generalizaciones para definir formas de modificación, simplemente como formas serranas (anular) y de la costa (fronto-occipital), tampoco están confirmadas (Dembo e Imbelloni 1938). Los documentos históricos sugieren que los inka identificaban grupos por sus prácticas de deformación craneana y que también estimaban que los modificados fueron intelectual y culturalmente inferiores (Garcilaso de la Vega 2004[1609]). Sin embargo, no se menciona si los chachapoya practicaban o no la deformación artificial de los cráneos. Nuestros datos pueden ser útiles para ver esta característica dentro de la muestra y la región.

En Kuélap hay muy poca evidencia de modificación craneal. De hecho, podemos decir que no era su costumbre. De los 341 cráneos bien preservados de Kuélap (masculinos n =159, femeninos $n=93$, jóvenes $n=89$ ), solamente un adulto joven femenino tuvo un cráneo claramente modificado, en el estilo anular oblicuo hecho por vendas y no por aplanamiento (Fig. 9). Así que este puede representar una persona no-local del sitio, pudiendo ser considerada como una extranjera (para una discusión de otros sitios con modificación craneal vea abajo).

\subsection{Patrones de heridas traumáticas}

Hay evidencia clara de trauma antemortem (huesos fracturados y soldados), y perimortem (fracturas no soldadas) en los restos óseos de Kuélap (Fig. 10). Las heridas antemortem pueden haber resultado de accidentes ambientales o por trauma interpersonal como la violencia social o la guerra - especialmente las fracturas ubicadas por el cráneo-, o conflicto social (Judd 2002). Los patrones de heridas en esta colección demuestran una prevalencia proporcional de ambos tipos de fracturas con frecuencias similares entre los individuos masculinos y femeninos (Tabla 6). Una investigación previa encontró la frecuencia de trauma antemortem interpersonal craneal en la región de Chachapoyas, pero menor que en otras regiones andinas donde el desarrollo de imperios y conflicto social fueron más evidentes arqueológicamente (Arkush y Tung 2013; Nystrom y Toyne 2014). Asimismo, nos sorprende que tanto individuos masculinos como femeninos demuestren porcentajes y tipos de fracturas similares, pues esperábamos una diferencia considerando que ellos fueron "guerreros» agresivos en conflicto constante. No hay evidencia clara para sugerir el prejuicio de violencia masculina. Sugerimos posibles diferencias sociales en la exposición a la violencia. Nystrom y Toyne (2014) encontraron índices más bajos de trauma craneal entre los restos esqueléticos de individuos de estatus más elevado de Los Pinchudos y Laguna Huayabamba. En Kuélap la frecuencia es un poco más alta, lo cual puede reflejar que en este centro más grande había un conjunto de varios individuos quizás de diferente estatus social, incluyendo gente de estatus más bajo (y más expuesto a eventos violentos). Estas interpretaciones de traumatismos craneales no incluyen las fracturas perimortem de los individuos encontrados en la «masacre» donde la gran mayoría presentó evidencia de fracturas craneales (Toyne y Narváez 2014). Pero se puede notar que había 19/219 (8,7\%) adultos del resto de los contextos mortuorios de Kuélap (no-«masacre») con evidencia de fracturas perimortem craneales, lo cual sugiere que murieron violentamente. Desafortunadamente, hasta ahora no existen otros estudios publicados para comparar esta frecuencia de traumatismos perimortem con otras poblaciones precolombinas andinas. 
En particular, hay dos tumbas de piedra en forma de colmena (Tumba 1, n=8 y Tumba 2, n=7) ubicadas al borde de la parte superior de la muralla, al lado oeste de la Plataforma Circular, las cuales contenían restos óseos, casi todos de hombres. Había solamente una mujer de mayor edad en la Tumba 1. Pero lo más interesante es que todos los individuos enterrados en la Tumba 1 tenían evidencia de traumatismos craneales, tanto antemortem como perimortem. Y en la Tumba 2 solamente $2 / 7$ no tenían evidencia de trauma. Estas tumbas juntas pueden representar quizás un grupo selecto de individuos que compartieron bastante exposición a la violencia física, como guerreros, así que fueron enterrados juntos. Otros contextos mortuorios de Kuélap pueden ser explorados así para entender mejor los patrones paleopatológicos en estas tumbas colectivas.

\section{Discusión}

Con todos estos datos estamos en condiciones de plantear nuestra discusión del perfil biológico de los individuos de Kuélap y sus vidas, incluyendo otros aspectos de salud evidente en los huesos. Hay varias condiciones importantes que pueden ser discutidas para explicar la variación que observamos, pero también hay consistencias interesantes con las descripciones etnohistóricas.

\subsection{Patrones de dimorfismo sexual}

Los modelos tradicionales de la apariencia física de los chachapoya, según las fuentes etnohistóricas, describen un dimorfismo sexual de «belleza femenina» $\mathrm{y}$ "ferocidad masculina», como cualidades de la población. Mientras los hombres son más altos que las mujeres, hay casos de considerable coincidencia en estatura, este rasgo es importante. Esto puede significar que tenemos: A) una muestra genéticamente variable o una muestra que incluye poblaciones distintas (grupos altos y bajos) (Frisancho 1976); B) variabilidad de estatus social que se relaciona por tener acceso a mejores recursos durante crecimiento y desarrollo, significando que algunos de los individuos de Kuélap estuvieron bastante estresados durante su niñez y no llegaron a una estatura promedio como otros, de modo que la desigualdad social se expresa en una forma de «retraso de crecimiento» (Steckel 1995). Otra posible explicación puede ser que bajo condiciones de selección natural (estrés) una población con un rango de variación amplia refleja condiciones ambientales positivas, donde todos los miembros del grupo, ambos altos y bajos son de «buena salud». Así, el factor ambiental y por convención, estrés social, que afecta a la población eran bajos; por lo tanto, Kuélap era un grupo variable y sano (Vercelloti et al. 2014). En comparación con Túcume de la costa norte, tanto hombres como mujeres chachapoya eran más altos y en comparación con otros grupos andinos también. La población inka de la sierra sur puede haber percibido a los chachapoya como más altos (Tabla 3). Pero la única muestra osteológica con estimación de estatura pertenece a Machu Picchu (Verano 2003), lo cual está interpretado como posibles yanacona, o sirvientes de los inka que fueron de origines regionales distintos de Machu Picchu.

En términos de la variación métrica estimada, los restos óseos de Kuélap demuestran diferencias en masa corporal e índice crural respecto de otros grupos andinos conforme con los resultados publicados (Weinstein 2005). Mientras el largo de las piernas no es notoriamente relevante, un cuerpo más robusto estimado para los chachapoya podría haber sido conocido y haber llegado a ser parte de la descripción del aspecto físico y fortaleza de los chachapoya. Mientras hay diferencias estadísticas, este análisis está basado en pocas muestras y hay una gran similitud en variación. Un factor para explicar esta similitud puede ser que en los tiempos tardíos prehispánicos había más movilidad y migración intrarregional — con poblaciones que se trasladan por el paisaje más frecuentementetanto en individuos masculinos como femeninos. Así, este cruzamiento crea poblaciones más homogéneas que unidades biológicas distintas o aisladas. Más aun, de acuerdo con los documentos históricos, es especialmente relevante para la región de Chachapoyas, que los inka desplazaron hasta el 50\% de los pobladores de la región en forma de 18 grupos de mitimae para consolidar el territorio y solamente insertaron unos pocos grupos de otras regiones (Schjellerup 1997). Entonces, 


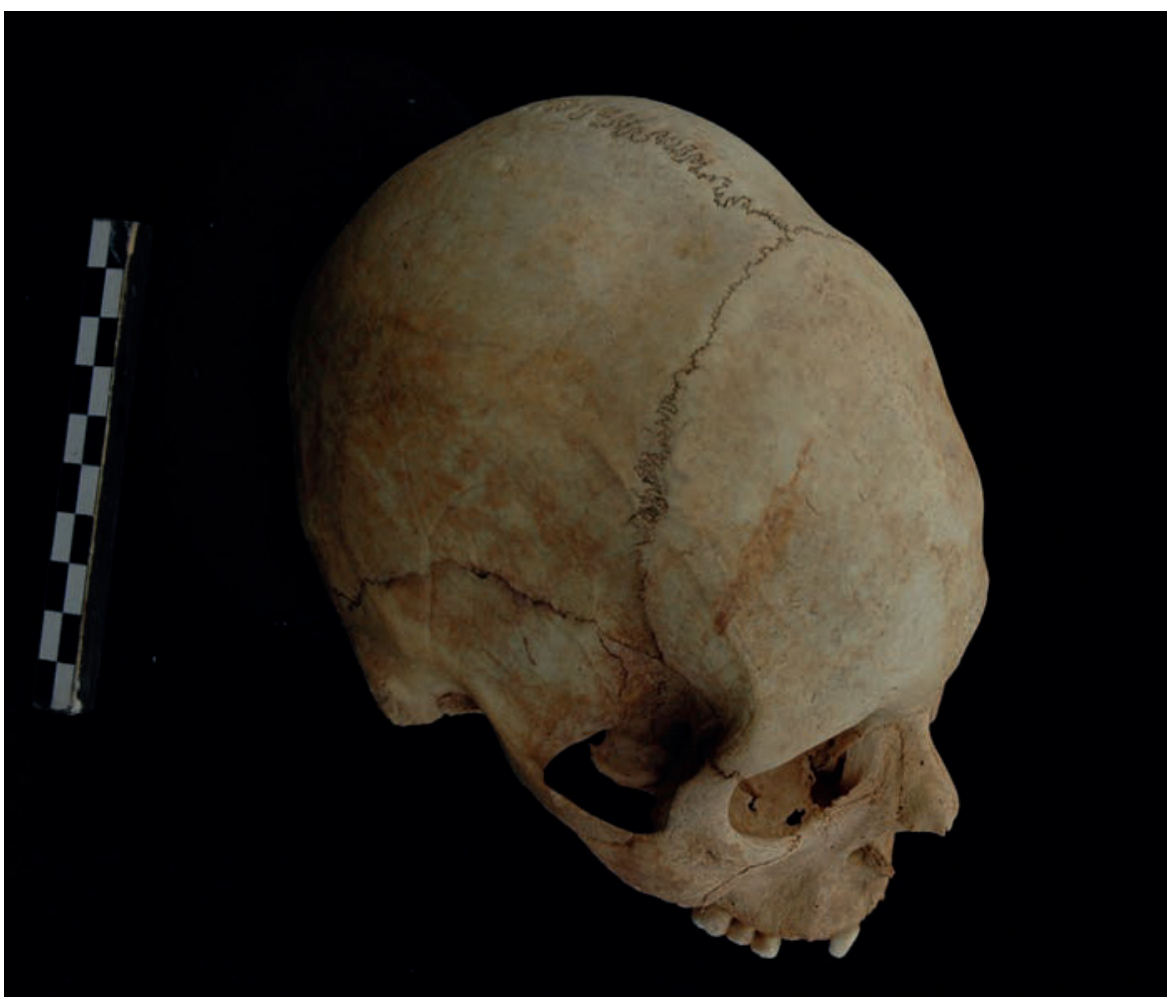

Figura 9. Cráneo de una mujer adulta con evidencia de modificación (foto por J.M. Toyne).

hubo bastante variación genética introducida en la región, lo que afectó la estatura, proporciones corporales y morfología (por la introducción de individuos de poblaciones de las sierras norteñas, centrales, sureñas y costa) ( $c f$. Guevara este número). Por lo tanto, este rango de variación puede ser el resultado de la adición genética y la reconfiguración política de poblaciones locales. No se puede verificar los cambios seculares de estatura en esta colección de Kuélap. Necesitaríamos grandes muestras óseas humanas pre inka para demostrar la influencia cronológica de tiempos pre y pos inka sobre estas poblaciones, así como datos de otras muestras óseas de distintas regiones.

\subsection{La modificación biocultural del cuerpo}

La belleza física es bastante difícil de evaluar con solamente los restos óseos. Hay muy poca evidencia de modificación craneana en esta muestra de Kuélap, lo cual sugiere que no era una práctica cultural. La investigación previa de Jakobsen et al. (1986-87) presentó resultados del estudio de una muestra de esqueletos de varios sitios mortuorios del distrito de Chuquibamba incluyendo 158 cráneos, de los cuales identificaron 16 (10\%) con modificación de la bóveda incluyendo varios estilos: de forma anular, tabular erecta y tabular oblicua. La frecuencia es baja, sin embargo, la variación es interesante porque no representa un solo estilo. El trabajo reciente de Toyne en el sitio La Petaca permitió recuperar un total de 56 cráneos de adultos, pero ninguno de ellos fue deformado, y tampoco se identificó modificación craneal en la colección de Laguna de los Cóndores. Entonces, la modificación craneal no fue una práctica típica en la región. Si la formación de la bóveda craneal refleja la presencia o integración de individuos foráneos de diferentes grupos culturales, en donde era normal modificar los cráneos de infantes para marcar su identidad social, había muy pocos individuos de estos lugares en Chachapoyas. La información actual puede sugerir que había muy poco contacto con estos grupos culturales. 


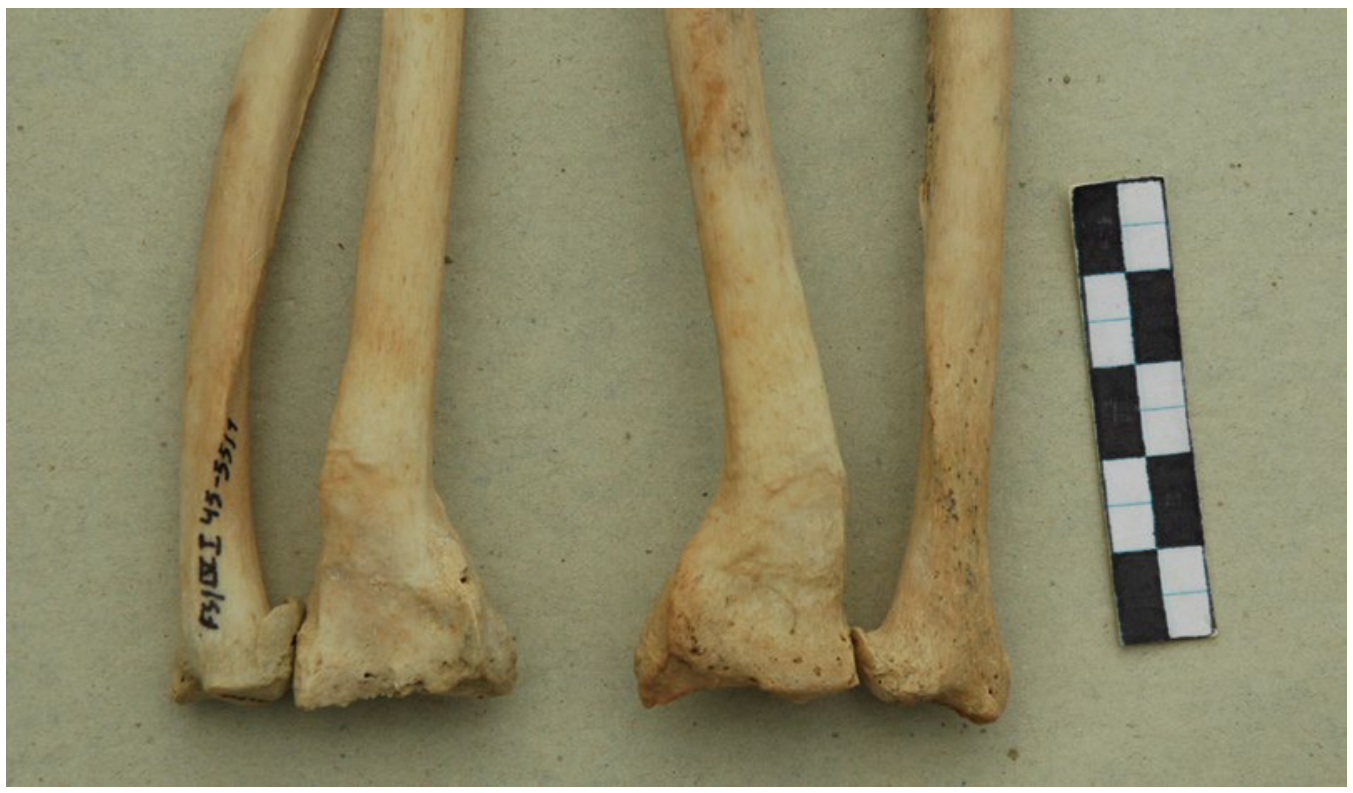

Figura 10. Foto de fracturas soldadas (ante mortem) de las muñecas de una mujer de edad media (30-44 años) observadas en Kuélap (foto por J.M. Toyne).

Los patrones de fracturas óseas revelan cambios en la forma física de los chachapoya por traumatismo accidental o interpersonal, indicado aspectos también de su comportamiento. Si los chachapoya fueron belicosos y guerreros sería más probable que los hombres mostraran más heridas craneales y también fracturas en el resto de sus cuerpos. En Kuélap hay evidencia de trauma craneal, pero no más alta que en otros regiones (Arkush y Tung 2013). La expectativa de más fracturas en los restos de hombres que en mujeres no fue observada; por lo tanto, no sirve para apoyar la reputación de los hombres como bravos guerreros (Nystrom y Toyne 2014). Las heridas poscraneales son consistentes entre ambos sexos, con accidentes de caídas en terreno agreste y difícil. Jakobsen et al. (1986-87) nos informan sobre lesiones traumáticas craneales en 18 de 158 (11,2\%) cráneos recuperados de seis sitios arqueológicos, donde los hombres son solo el 8,2\% de los observados. Pero como la colección procede de contextos disturbados sin fechas absolutas, la frecuencia y tipos de fracturas poscraneanas no pueden ser determinados.

Las lesiones sobre el hueso de la bóveda craneana indican intervenciones después de una herida y pueden también representar evidencia de traumatismos resultantes de violencia interpersonal o accidental (Toyne 2011, 2015c). Desafortunadamente no hay datos publicados de momias bien preservadas para poder entender los estilos antiguos en el peinado de cabello (la moda diaria o la moda funeraria), para ver como esto afectó al cuero cabelludo. Es posible que las heridas grandes pudieran haber afectado la percepción de la belleza física de la persona. En este caso tenemos tanto individuos femeninos como masculinos con este tipo de traumatismos. Estas lesiones ¿pudieron haberse producido si la cabeza estuvo protegida por una gorra o un casco? Sabemos que en estas sociedades precolombinas existían gorras o tuvieron estilos decorativos de cabello pero, luego de producidas, ¿estas lesiones fueron visibles? ¿Cómo podemos interpretar el significativo de estas heridas? ¿Fueron identificadas como deformidades? $\mathrm{O}$ ¿pudieron haber sido reconocidas como insignias de honor o supervivencia después de un combate feroz? Es imposible de saber el impacto de estas lesiones sobre su «belleza».

De otro lado, también hay evidencia abundante de trepanaciones (cirugía del cráneo) en la muestra de Kuélap, registrándose por lo menos 21 individuos (ambos mujeres y hombres) con 


\begin{tabular}{|c|c|c|c|c|c|c|c|}
\hline \multirow{2}{*}{ Fracturas accidentales } & \multirow{2}{*}{\multicolumn{2}{|c|}{ Ubicación }} & \multirow{2}{*}{$\begin{array}{l}\text { Total } \\
371\end{array}$} & \multicolumn{2}{|c|}{ Masculino } & \multicolumn{2}{|c|}{ Femenino } \\
\hline & & & & 226 & & 145 & \\
\hline & hombro/brazo superior & & 11 & 4 & $2 \%$ & 7 & $5 \%$ \\
\hline & vertebral & & 19 & 10 & $4 \%$ & 9 & $6 \%$ \\
\hline & pierna superior & & 4 & 3 & $1 \%$ & 1 & $1 \%$ \\
\hline & pierna inferior/pies & & 38 & 32 & $14 \%$ & 6 & $4 \%$ \\
\hline & & Total & 72 & 49 & $22 \%$ & 23 & $16 \%$ \\
\hline Fracturas interpersonales & & & 252 & 159 & & 93 & \\
\hline & craneales & & 66 & 35 & $22 \%$ & 31 & $33 \%$ \\
\hline & faciales & & 27 & 23 & $14 \%$ & 4 & $4 \%$ \\
\hline & antebrazo/manos & & 35 & 19 & $8 \%$ & 16 & $11 \%$ \\
\hline & torso/costillas & & 28 & 16 & $7 \%$ & 12 & $8 \%$ \\
\hline & & Total & 156 & 93 & & 63 & \\
\hline & Fracturas múltiples & & 46 & 24 & $11 \%$ & 22 & $15 \%$ \\
\hline
\end{tabular}

Tabla 6. Distribución de traumatismos ante mortem en los esqueletos de adultos.

trepanaciones y evidencia de éxito en aproximadamente 78\% de los casos. Muchas trepanaciones han sido identificadas en la región de Chachapoyas (Nystrom 2007; Ruiz Estrada 1994, 1999) y aunque a veces están asociados con trauma craneal, no es siempre posible de correlacionar la trepanación con heridas violentas. En Kuélap solamente 42,0\% de los individuos con trepanaciones tenía evidencia de otras fracturas antemortem o perimortem, pero solamente dos de las trepanaciones $(10,0 \%)$ fueron directamente asociadas con fracturas craneales. La trepanación es una práctica en la región que parece haber sido practicada por una variedad de razones terapéuticas (Toyne 2014). Del mismo modo, estos varios tipos de fracturas soldadas en el cráneo sugieren que la vida era difícil y había conflicto social, pero al final no es fácil decir si los chachapoya fueron más beligerantes o guerreros que otros grupos andinos.

Hay varios otros datos paleopatológicos que también pueden ser observados en los restos óseos de Kuélap que posiblemente indican aspectos relacionados al estatus de salud relativa de la población y aspectos de su bienestar. Estas observaciones preliminares son parte de estudios en curso, sin embargo, estos indican que las lesiones de estress no-específicas son similares a otras poblaciones antiguas andinas. En esta muestra de Kuélap hay evidencia de osteoartritis, una condición degenerativa de las articulaciones, frecuentemente asociada con la vejez y varios tipos de actividades habituales. Los patrones de osteoartritis sugieren que los hombres fueron más activos que las mujeres, especialmente en las edades más jóvenes, como esperábamos. Sin embargo, en los individuos de edad mayor no se observó el mismo nivel de cambios degenerativos en las articulaciones, lo cual puede sugerir que individuos con vida menos activa llegaron a tener más longevidad. Esto podría reflejar un tipo de diferencia social en actividades laborales en la comunidad (Manoni y Toyne 2015). Quizás tenemos evidencia de un grupo de elite social quien tenía roles especializados que no implicaban una actividad física cotidiana significativa. 


\section{Conclusiones}

Este análisis representa la primera investigación detallada sobre la morfología y patrones físicos de los antiguos pobladores de Kuélap. Estos análisis óseos demuestran un variado rango de información e interpretaciones para una amplia colección de la región de Chachapoyas, aunque, como siempre, un mayor número de esqueletos podrá mejorar nuestro entendimiento de la variación regional y posibles diferencias sociales. El huaqueo intensivo de las tumbas nos dificulta observar un mejor análisis individual, pero igual, los contextos mezclados puedan presentar datos óseos valiosos. Otros sitios no tienen colecciones suficientemente preservados ni contextualizados para poder compararlos con la colección de Kuélap, de modo que esperamos nuevas investigaciones arqueológicas para colaborar y avanzar estas conclusiones. Los documentos históricos nos presentan un retrato de la gente chachapoya que no está conectado claramente con los restos arqueológicos. Utilizando esta reconstrucción biológica, los chachapoya pudieron haber tenido mayor estatura y estar físicamente adaptados a su medio ambiente, presentando rasgos biológicos distintos a otros grupos precolombinos. Otras características se muestran más relevantes, como la resistencia social de los chachapoya frente a los inka y es posiblemente por eso que los inka describieron a los chachapoya así en las crónicas. Pero la variación regional y la organización social de los varios subgrupos de esta región (chilchos, chacha, etc.) requieren más avances en la investigación arqueológica para verificar las correlaciones culturales entre estos grupos y los patrones de violencia en la zona antes de la llegada de los inka, así, los estudios bioarqueológicos de los entierros contribuirán en el futuro con valiosa información.

Es necesario refinar la cronología de los entierros de Kuélap mejorar el conocimiento de los cambios temporales en muchos de estos indicadores óseos, pero también necesitamos continuar con los estudios de paleopatologías para avanzar nuestros conocimientos sobre la historia y la vida de los chachapoya. Estos modelos sugieren un grado de diferenciación social. Con nuevos estudios de las distintas prácticas mortuorias, podremos conocer mejor las diversas historias de los Chachapoya y pues ellas se encuentran plasmadas en sus restos óseos.

\section{Agradecimientos}

Queremos agradecer mucho a Anna y Warren por la organización de este simposio y la edición de este volumen. Agradecemos todos los participantes el Proyecto Arqueológico de Kuélap durante todos sus años: el arquitecto Raúl Zamalloa, los arqueólogos Bernarda Delgado, Tomás Campos, Edwin Blas, Willy Chiguala, Julio Rodríguez, Yolanda Bullón e Ivy Rengifo. Asimismo, reconocemos el apoyo de varias fuentes como el Ministerio de Cultura de Perú del Perú, incluyendo el director de Amazonas, José Trauco y el arqueólogo Manuel Malaver y las fuentes financieras: MINCETUR, Plan Nacional COPESCO, World Monuments Fund. La primera autora quiere agradecer todos los asistentes en la acumulación de los datos para este proyecto: Daysi Ańasco, Magali Tuesta, Natalia Guzmán, Alejandra Ortiz, Lori Epstein y Armando Anzellini. También a mis colegas en bioarqueología: John Verano, Ken Nystrom, Sonia Guillén, Mellisa Lund y María del Carmen Vega. Finalmente, la primera autora reconoce los fondos aportado por National Geographic (EC0374-08), la Fundación Petzl (Francia) y el Departamento de Antropología y el Colegio de Ciencias de la Universidad de Florida Central.

\section{Notas}

${ }^{1}$ Se calculó el dimorfismo sexual en este estudio por la calculación $=1-$ (promedio de estatura femenino/promedio de estatura masculino) ${ }^{*} 100$. 


\section{REFERENCIAS}

Andrushko, V., E. C. Torres Pino y V. Bellifemine

2006 The burials at Sacsahuaman and Chokepukio: a bioarchaeological case study of imperialism from the capital of the Inka empire, Nawpa Pacha 28, 63-92.

Arkush, E. y T.A. Tung

2013 Patterns of war in the andes from the archaic to the late horizon: insights from settlement patterns and cranial trauma, Journal of Archaeological Research 21(4), 307-369.

Auerbach, B. M. y C. Ruff

2010 Stature estimation formulae for indigenous North American populations. American Journal of Physical Anthropology 141:190-207.

Bandelier, A.

1940 Los indios y las ruinas aborígenes cerca de chachapoyas en el norte del Perú, Chaski 1(2),13-59.

Barraza Lescano, $S$.

2003 Un lector desconocido del jesuita Blas Valera: Francisco de Herrera Maldonado, Boletín del Instituto Riva Agüero 30, 407-412.

Basadre, M.

1892 Torre de Babel en el Perú, Boletín de la Sociedad Geográfica de Lima Tomo 1(10-12), 444-448.

Blom, D. E.

2005 Embodying borders: human body modification and diversity in Tiwanaku society, Journal of Anthropological Archaeology 24, 1-24.

Bracamonte, $\mathrm{F}$.

2002 Los Pinchudos: un estudio preliminar de su población, Sian 12, 14-15.

2004 Los Pinchudos: un acercamiento a las características físicas de su población, Sian 15, 18-19.

Bradley, R.

2008 The architecture of Kuelap, VDM Verlad Dr. Muller, Saarbrücken, Germany.

Buikstra, J. E. y D. H. Ubelaker (eds.)

1994 Standards for data collection from human skeletal remains, Arkansas Archaeological Survey, Fayetteville.

Calancha, A.

1972 Crónica moralizada del orden de san augustin en el Peru, con sucesos exemplares de esta monarquia, Pedro

[1638] Lacavalleria, Barcelona.

[Cieza de Leon, P.

1984 La primera parte de la crónica del perú, Historia 16, Madrid.

[1553]

1880 La segunda parte de la crónica del perú, Imprenta Manuel Gines Hernandez, Madrid.

[1553]

Cobo, B.

1990 Inka religion and customs [traducción de R. Hamilton], University of Texas Press, Austin.

[1653]

Del Angel, A. y H. B. Cisneros

2004 Technical note: modification of regression equations used to estimate stature in mesoamerican skeletal remains, American Journal of Physical Anthropology 125(3), 264-265.

Dembo, A. y J. Imbelloni

1938 Deformaciones intencionales del cuerpo humano, Jose Anesi: Humanior: Biblioteca del Americanista Moderno, Buenos Aires.

Epstein, L. y J. M. Toyne

2015 When space is limited: a spatial exploration of pre-hispanic Chachapoya mortuary and ritual microlandscape, en: A. Osterholtz (ed.), Theoretical approaches to analysis and interpretation of commingled human remains, 95-124, Springer, New York. 


\section{Espinoza Soriano, W.}

1967 Los señoríos étnicos de Chachapoyas y la alianza hispano-chacha: visitas, informaciones y memoriales ineditos de 1572-1574, Revista Histórica (Lima) 30, 224-333.

Friedrich, K. M., S. Nemec, C. Czerny, H. Fischer, S. Plischke, A. Gahleitner, T. B. Viola, H. Siedler y S. Guillén

2010 The story of 12 Chachapoyan mummies through mulitdetector computed tomography, European Journal of Radiology 68(3), 143-150.

Frisancho, A. R.

1976 Growth and morphology at high altitude, en: P. T. Baker y M. Little (eds.), Man in the Andes, 180-207, Dowden, Hutchinson and Ross, Inc., Shroudsburg.

Gagnon, C. M.

2008 Bioarchaeological investigations of pre-state life at Cerro Oreja, en: L. J. Castillo Butters, H. Bernier, G. Lockard y J. Rucabado (eds.), Arqueologia Mochica nuevos enfoques, 173-185, Instituto Francés de Estudios Andinos/Fondo Editorial PUCP, Lima.

Gaither, C., K. Koschmieder y G. P. Lombardi

2008 En la tierra de los gigantes: un nuevo «gigante» encontrado en el sitio nor-andino de Chichita, Peru, Arqueobios 2, 28-39.

Garcilaso de la Vega, I.

2004 Comentarios reales de los Inkas, Biblioteca, Ayacucho.

[1609]

Genovés, $S$.

1967 Proportionality of long bones and their relation to stature among Mesoamericans, American Journal of Physical Anthropology 26, 67-78.

\section{Gonzáles Valencia, D. y J. M. Toyne}

2014 Prospeccion e investigacion de contextos arqueologicos y funerarios del sitio arqueologico de La Petaca (PALP), informe presentado al Ministerio de Cultura de Perú.

\section{Guaman Poma de Ayala, F.}

1980 El primer nueva cronica y buen gobierno. Tomo 1 [traducción de J. Urioste], Coleccion america nuestra 31,

[1615] Siglo Veintiuno Editores, S.A., Mexico City.

Guengerich, A.

2014 The architect's signature: the social production of a residential landscape at Monte Viudo, Chachapoyas, Peru, Journal of Anthropological Archaeology 34, 1-16.

Guillén, S. E.

2002 Las momias de Laguna de los Condores, en: E. Gonzalez y R. Leon (eds.), Chachapoyas, el reino perdido, 345-387, AFP Integra, Lima.

2003 Keeping ancestors alive: the mummies from Laguna de los Cóndores, Amazonas, Peru, Proceedings of the 4th World Congress on Mummy Studies, September 4-10, 2001, 162-164. Nuuk, Greenland.

Guillén, S. E., G. Conlogue, A. Bravo y H. Seidler

2004 Las momias de la Laguna de los Cóndores: Una evaluacián radiográfica. Sian 15, 22-23.

Heyerdahl, T., D. H. Sandweiss y A. Narváez

1995 Pyramids of Túcume: The quest for Peru's forgotten city. Thames and Hudson Publishers, New York.

Horkheimer, $\mathrm{H}$.

1958 Algunas consideraciones acerca de la arqueologia en el valle de Utcubamba, Actas y Trabajos del II Congreso Nacional de Historía del Peru, Época PreHispanica I, 71-90.

Hyland, $S$.

2003 The Jesuit and the Inkas: the extraordinary life of Padre Blas Valera, The University of Michigan Press, Ann Arbor.

Jakobsen, J., J. B. Jorgensen, L. K. Jorgensen y I. Schjellerup

1986-87 Cazadores de cabezas» en sitios pre-Inka de Chachapoyas, Amazonas, Revista del Museo Nacional (Lima) $48,139-185$. 
Judd, M. A.

2004 Trauma in the city of Kerma: ancient versus modern injury patterns, International Journal of Osteoarchaeology 14(1), 34-51.

\section{Kauffmann Doig, F.}

2009 Constructores de Kuélap y Pajatén: los chachapoya(s), Derrama Magisterial, Lima.

Kellner, C. y M. J. Schoeninger

2008 Wari's imperial influence on local Nasca diet: The stable isotope evidence, Journal of Anthropological Archaeology 27(2), 226-243.

Kieffer, P.

1910 Une excusion a Cuelap. Department d'Amazonas, Perou. Extraits des notes de voyage, E. Rosay, Lima.

Koschmieder, K. y C. Gaither

2010 Tumbas de guerreros chachapoya en abrigos rocosos de la provincia de Luya, departamento de Amazonas, Arqueologia y Sociedad 22, 1-30.

Lanfranco, L. P. y S. Eggers

2013 Modo de vida y expectativas de salud en poblaciones del Período Formativo de la costa norte del Perú: Evidencias bioanthropologicas del sitio Puemape, Latin American Antiquity 24(2), 191-216.

Langlois, L.

1934 Las ruinas de Cuelap, Boletín de la Sociedad Geográfica de Lima 51, 20-34.

Lasker, G. W.

1962 Differences in anthropometric measurements within and between three communities in Peru, Human Biology 34, 63-67.

Lerche, P.

1995 Los chachapoyas y los simbolos de su historia, Servicios Editorials Cesar Gayoso, Lima.

Lozada, M. C. y J. E. Buikstra

2005 Pescadores and labradores among the señorio of Chiribaya in southern Peru, en: R. M. Reycraft (ed.), Us and them: archaeology and ethnicity in the Andes, 206-225, The Cotsen Institute of Archaeology, University of California, Los Angeles.

Manoni, Z. y J. M. Toyne

2015 Osteoarthritis in the Andes: Prevalence and patterning of disease among pre-columbian agro-pastoralists from Kuelap, ponencia presentada en la reunión de la Paleopathology Association, St. Louis.

McGraw, J., M. Ocina, D. Sharon y C. Torres Mas

1997 Kuélap ¿un observatorio solar? Revista del Museo de Arqueología, Antropología e Historia 7, 185-204.

Murúa, Martin

1987 Historia General del Perú. Editado por M. Ballesteros. Vol. 35, Cronicas De America. Historia 16, [1590] Madrid.

\section{Narváez Vargas, A.}

1987 Kuélap: Una cuidad fortificada en los andes nor-orientales de Amazonas, Perú, en: V. Rangel Flores (ed.), Arquitectura y arqueología pasado y futuro de la construcción en el Perú, 115-142, Universidad de Nacional Pedro Ruiz Gallo, Lambayeque.

1996a La fortaleza de Kuélap, Arkinka 13, 90-98.

1996b La fortaleza de Kuélap, Arkinka 12, 92-108.

2013 Kuélap: centro del poder politico y religioso de los Chachapoyas, en: F. Kauffman-Doig (ed.), Los Chachapoyas, 87-160, BCP Coleccion de Arte y Tesoros Del Perú, Lima.

Nystrom, K. C.

2004 Trauma e identidad entre los chachapoyas. Sian 15, 20-21.

2005 Chachapoya mummies from the Laguna Huayabamba, Journal of Biological Research 80(1), 197-200.

2006 Late Chachapoya population structure prior to Inka conquest, American Journal of Physical Anthropology 131, 334-342.

2007 Trepanation in the Chachapoya region of northern Peru, International Journal of Osteoarchaeology 17, 39-51. 
2009 The reconstruction of identity: a case study from Chachapoya, Peru, en: K. J. Knudson y C. Stojanowski (eds.), Bioarchaeology and identity in the Americas, 82-102, University of Florida Press, Gainsville.

Nystrom, K. C. y J. M. Toyne

2014 «Place of strong men». Skeletal trauma and the (re)construction of Chachapoya identity, en: C. J. Knüsel y M. Smith (eds.), The bioarchaeology of human conflict: traumatised bodies from earliest prehistory to the present, 371-388. Routledge Press, New York.

Pachacuti-yamqui Salcamayhua, J. S. C.

1963 An account of the antiquities of Peru [traducción de C. R. Markham], Burt Franklin Publisher, New York. [1620]

Pia, G. E.

1988 Osteological report from excavations at Kuelap, Instituto Nacional de Cultura de Chachapoyas, Amazonas, informe en posesión del autor.

Pizzaro, P.

1986 Relacion del descubirmiento y conquista de los reinos del Perú, Fondo Editorial PUCP, Lima.

[1557]

Pomeroy, E.

2013 Biomechanical insights into activity and long distance trade in the south-central Andes (A.D.500-1450), Journal of Archaeological Science 40, 3129-3140.

Pomeroy, E. y J. Stock

2012 Estimation of stature and body mass from the skeleton among coastal and mid-altitude Andean populations, American Journal of Physical Anthropology 147, 264-279.

Reichlen, H. y P. Reichlen

1950 Rechereches archeologiques dans les Andes du haut Utcubamba, Journal de la Société des Americanistes 39, 219-246.

Ruff, C. B.

1992 Biomechanical analyses of archaeological human skeletal samples, en: S. R. Saunders y M. A. Katzenberg (eds.), Skeletal biology of past peoples: Research methods, 37-58, Wiley-Liss, New York.

Ruiz Barcellos, J.

2004 Purum llacta: Centro poblado chachapoya dedicado a la agricultura, Sian 9(15), 10-11.

2007 Arqueologia y arquitectura de Yalape en la Provincia de Chachapoyas - Departmento de Amazonas, Arkinka 136, 84-91.

Ruiz Estrada, A.

1972 La alfareria de Cuelap: tradición y cambio, tesis de bachillerato, Escuela de Arqueología, Universidad Nacional Mayor de San Marcos, Lima.

1994 La cirugia prehispanica en el departamento de Amazonas, Perú, Sequilao 97, 149-173.

1999 Craneos trepanados de Lamud, El Torreón 3(29), 4.

2008 Las cavernas y el poblamiento prehispánico de la Provincia de Chachapoyas, Arqueologia: Investigaciones Sociales 7(20), 35-62.

2009 Sobre las formas de sepultamiento prehispanicas en Kuélap, Amazonas, Arqueología y Sociedad 20, 1-16.

2011a Amazonas: Arqueologia y historia, Universidad de Alas Peruanas, Lima.

2011b La mita de chachapoyas del año 1586, Investigaciones Sociales 15(27), 359-374.

Salinas Loyola, J.

1965 Historia indica, Biblioteca de Autores Espańoles, vol. II., Madrid.

[1571]

Sarmiento de Gamboa, P.

1967 History of the Inka [traducción de C. R. Markham], Kraus Reprint Limited, Nendeln.

[1572]

Schjellerup, I.

1997 Inkas and Spaniards in the conquest of Chachapoyas. Archaeological and ethnohistorical research in the northeastern Andes of Peru, Gotarc, Series B, Gothenburg Archaeologial Theses, 7. Goteborg University, Goteborg. 
2008 Sacando a los caciques de la oscuridad del olvido. Etnias chachapoya y chilcho. Bulletin de L'Institut Francais d'Etudes Andines 37(1), 111-122.

Steckel, R. H.

1995 Stature and standard of living, Journal of Economic Literature 33, 1903-1940.

Sutton, P.

1997 A translator's dilemma, en: K. Simms (ed.), Translating sensitive texts: linguistic aspects. 67-75, Rodopi, Amsterdam.

Tomasto, E.

2013 Los paracas: las momias y los esqueletos, en: Ministro de Cultura, Paracas, 67-76. Museo National de Arqueologia, Antropologia e Historia del Perú, Ministerio de Cultura, Lima.

Torres-Rouff, C.

2002 Cranial vault modification and ethnicity in the Middle Horizon San Pedro de Atacama, Chile, Current Anthropology 42(1), 163-171.

2011 Hiding inequality beneath prosperity: patterns of cranial injury in Middle Period San Pedro de Atacama, northern Chile, American Journal of Physical Anthropology 146:28-37.

Toyne, J. M.

2002 Tales woven in their bones: the osteological examination of the human skeletal remains from the Stone Temple at Túcume, Perú, tesis de maestría, Department of Anthropology, The University of Western Ontario, London.

2006 Analysis of human skeletal remains from the Late Intermediate Period occupation of Farfán, Perú, informe interno elaborad por la Dra. Carol Mackey, University of California North Ridge.

2008 They offered their hearts and their heads: A bioarchaeological analysis of ancient human sacrifice on the northern coast of Peru, tesis de doctorado, Anthropology, Tulane University, New Orleans.

2011 Possible cases of scalping from northern prehispanic Peru, International Journal of Osteoarchaeology 21(2), 229-242.

2014 You can trepan if you want to or you can leave your skull alone: patterns in ancient cranial surgery at Kuelap, Chachapoyas, Peru, American Journal of Physical Anthropology 153(S58), 255.

2015a Análisis osteológico de los restos humanos de Túcume (resumen y inventario de todos las etapas). Informe interno elaborado por la Lic. Bernarda Delgado, Túcume, Peru.

2015b Tibial surgery in ancient Peru, International Journal of Paleopathology 8, 29-35.

2015c Variation in large ectocranial lesions from pre-columbian Kuelap, Peru, International Journal of Paleopathology 11, 30-44.

Toyne, J. M. y A. Narváez Vargas

2014 The fall of Kuelap: Bioarchaeological analysis of death and destruction on the eastern slopes of the Andes, en: A. K. Scherer, J. W. Verano y J. Pillsbury (eds.), Conflict, conquest, and the performance of war in precolumbian America, 345-368. Dumbarton Oaks Research Institute, Washington, D.C.

Toyne, J. M., W. B. Church, L. Coronado Tello y R. Morales Gamorra

2017 Exploring imperial expansion using an isotopic analysis of paleodietary and paleomobility indicators in Chachapoyas, Peru, American Journal of Physical Anthropology 162(1), 51-72.

Tran, V.

2014 Determining the minimum number of individuals and significance of the Kuelap ossuary, Chachapoyas, Peru, tesis de licenciatura, Department of Anthropology, University of Central Florida, Orlando.

Tung, T. A.

2007 Trauma and Violence in the Wari Empire of the Peruvian Andes: Warfare, Raids, and Ritual Fights. American Journal of Physical Anthropology 133(3), 941-956.

Ubelaker, D. H.

1989 Human skeletal remains: Excavation, analysis, interpretation. Second edition, 2da ed., Aldine Publishing Company, Chicago.

Valera, B.

1945 Las Costumbres Antiguas del Perú y la Historia de los Incas (siglo XVI). Editado por F. A. Loayza, Lima

[1590?] 
Verano, J. W.

1997 Physical characteristics and skeletal biology of the Moche population at Pacatnamu, en: C. Donnan y G. A. Cock (eds.), The Pacatnamu papers. The Moche occupation, vol. 2, 189-213, UCLA Fowler Museum of Cultural History, Los Angeles.

2001 The Physical Evidence of Human Sacrifice in Ancient Peru. In Ritual Sacrifice in Ancient Peru, edited by E. P. Benson and A. G. Cook, pp. 165-184. University of Texas Press, Austin.

2003 Human skeletal remains from Machu Picchu: a reexamination of the Yale Peabody museum's collections, en: R. L. Burger y L. C. Salazar (eds.), The 1912 Yale Peruvian scientific expedition collections from Machu Picchu: Human and animal remains, vol. 85, 65-117, Yale University Publications in Anthropology, New Haven.

Verano, J. W. y J. M. Toyne

2011 Estudio bioantropológico de los restos humanos del Sector II, Punta Lobos, valle de Huarmey, en: M. Giersz y I. Ghezzi (eds.), Arqueologia de la costa de Áncash, 449-474, ANDES: Boletín del Centro de Estudios Precolombinos de la Universidad de Varsovia, Lima.

Vercellotti, G., B. A. Piperata, A. M. Agnew, W. M. Wilson, D. L. Dufour, J. C. Reina, R. Boano, H. M. Justus, C. S. Larsen, S. D. Stout y P. W. Sciulli

2014 Exploring the multidimensionality of stature variation in the past through comparisons of archaeological and living populations, American Journal of Physical Anthropology 155(2), 229-242.

Weinstein, K. J.

2005 Body proportions in ancient Andeans from high and low altitudes, American Journal of Physical Anthropology 128(3), 569-585.

Fecha de recepción: 30/05/2016

Fecha de aceptación: 07/02/2017 
